\title{
An optimized derivative of an endogenous CXCR4 antagonist prevents atopic dermatitis and airway inflammation
}

\author{
Mirja Harms ${ }^{\mathrm{a}}$, Monica M.W. Habib ${ }^{\mathrm{b}}$, Simona Nemska ${ }^{\mathrm{c}}$, \\ Antonella Nicolò $^{\mathrm{d}}$, Andrea Gilg ${ }^{\mathrm{a}}$, Nico Preising ${ }^{\mathrm{e}}$, Pandian Sokkar ${ }^{\mathrm{f}, \mathrm{g}, \mathrm{h}}$, \\ Sara Carmignani ${ }^{i}$, Martina Raasholm ${ }^{j}$, Gilbert Weidinger ${ }^{j}$, \\ Gönül Kizilsavask ${ }^{\mathrm{k}}$, Manfred Wagner ${ }^{\mathrm{k}}$, Ludger Ständker ${ }^{\mathrm{e}}$, \\ Ashraf H. Abadi ${ }^{\text {b }}$, Hassan Jumaa ${ }^{\text {d }}$, Frank Kirchhoff ${ }^{\mathrm{a}}$, \\ Nelly Frossard ${ }^{c}$, Elsa Sanchez-Garcia ${ }^{\text {f,g }}$, Jan Münch ${ }^{\mathrm{a}, \mathrm{e}, *}$
}

\author{
${ }^{a}$ Institute of Molecular Virology, Ulm University Medical Center, Ulm 89081, Germany \\ ${ }^{\mathrm{b}}$ Department of Pharmaceutical Chemistry, Faculty of Pharmacy and Biotechnology, German University in Cairo, \\ Cairo 11835, Egypt \\ ${ }^{\mathrm{c}}$ Laboratoire D'Innovation Thérapeutique, UMR7200 CNRS/Université de Strasbourg and LabEx MEDALIS, \\ Faculté de Pharmacie, Illkirch 67412, France \\ ${ }^{\mathrm{d} I n s t i t u t e}$ of Immunology, Ulm University Medical Center, Ulm 89081, Germany \\ ${ }^{\mathrm{e}}$ Core Facility Functional Peptidomics, Ulm University Medical Center, Ulm 89081, Germany \\ ${ }^{\mathrm{f}}$ Center of Medical Biotechnology, University of Duisburg-Essen, Duisburg 47057, Germany \\ ${ }^{\mathrm{g}}$ Max-Planck-Institute for Coal Research, Düsseldorf 45470, Germany \\ ${ }^{\mathrm{h}}$ Faculty of Allied Health Sciences, Chettinad Hospital and Research Institute, Chettinad Academy of Research and \\ Education, Kelambakkam 603103, India \\ ${ }^{\mathrm{i}}$ Max-Planck-Institut für Molekulare Physiologie, Dortmund 44227, Germany \\ ${ }^{\mathrm{j}}$ Institute of Biochemistry and Molecular Biology, Ulm University, Ulm 89081, Germany \\ ${ }^{\mathrm{k}}$ Max Planck Institute for Polymer Research, Mainz, 55128, Germany
}

Received 21 September 2020; received in revised form 10 November 2020; accepted 1 December 2020

\section{KEY WORDS \\ CXCR4 antagonist;}

Abstract Aberrant CXCR4/CXCL12 signaling is involved in many pathophysiological processes such as cancer and inflammatory diseases. A natural fragment of serum albumin, named EPI-X4, has

\footnotetext{
*Corresponding author. Tel.: +49 731 50065150; fax: +49 73150065154 .

E-mail address: jan.muench@uni-ulm.de (Jan Münch).

Peer review under responsibility of Chinese Pharmaceutical Association and Institute of Materia Medica, Chinese Academy of Medical Sciences. 
Asthma;

Allergy;

Inflammation;

Atopic dermatitis previously been identified as endogenous peptide antagonist and inverse agonist of CXCR4 and is a promising compound for the development of improved analogues for the therapy of CXCR4associated diseases. To generate optimized EPI-X4 derivatives we here performed molecular docking analysis to identify key interaction motifs of EPI-X4/CXCR4. Subsequent rational drug design allowed to increase the anti-CXCR4 activity of EPI-X4. The EPI-X4 derivative JM\#21 bound CXCR4 and suppressed CXCR4-tropic HIV-1 infection more efficiently than the clinically approved small molecule CXCR4 antagonist AMD3100. EPI-X4 JM\#21 did not exert toxic effects in zebrafish embryos and suppressed allergen-induced infiltration of eosinophils and other immune cells into the airways of animals in an asthma mouse model. Moreover, topical administration of the optimized EPI-X4 derivative efficiently prevented inflammation of the skin in a mouse model of atopic dermatitis. Thus, rationally designed EPI$\mathrm{X} 4 \mathrm{JM} \# 21$ is a novel potent antagonist of CXCR4 and the first CXCR4 inhibitor with therapeutic efficacy in atopic dermatitis. Further clinical development of this new class of CXCR4 antagonists for the therapy of atopic dermatitis, asthma and other CXCR4-associated diseases is highly warranted.

(C) 2021 Chinese Pharmaceutical Association and Institute of Materia Medica, Chinese Academy of Medical Sciences. Production and hosting by Elsevier B.V. This is an open access article under the CC BY-NC-ND license

(http://creativecommons.org/licenses/by-nc-nd/4.0/)

\section{Introduction}

The CXCR4/CXCL12 signaling axis plays a pivotal role in numerous biologic processes, i.e., organ development, hematopoiesis, vascularization, cell and tissue renewal, hematopoietic stem cell retention, inflammation, and immune control ${ }^{1-5}$. In addition, deregulation of this axis, e.g., by overexpression of CXCR4, is associated with a variety of diseases, such as tumor development, progression and metastasis, neurodegenerative and autoimmune disorders, as well as immunodeficiencies or inflammatory diseases, including atopic dermatitis and several forms of asthma $^{6-11}$. CXCR4 is a long-known drug target and several small molecules, peptide or antibody-based CXCR4 antagonists are currently in preclinical and clinical development ${ }^{12}$. However, the only clinically used CXCR4 antagonist is Plerixafor (Mozobil, AMD3100), which is approved as stem cell mobilizing agent in autologous transplantation of bone marrow cells in patients with non-Hodgkin's lymphoma or multiple myeloma, but not suitable for the treatment of chronic disease because of significant adverse effects $^{13,14}$.

One CXCR4/CXCL12-linked disease is asthma, a pathologic overresponse (airway hyper-responsiveness) to a wide variety of stimuli. Inhaled allergens, for example, are detected by pattern recognition receptors on the surface of airway epithelial cells. This triggers secretion of a variety of inflammatory cytokines which stimulate, e.g., lung-associated dendritic cells, that migrate into draining lymph nodes and induce a type 2 allergic response by activation of effector cells. Eosinophilia and increased influx of $\mathrm{TH} 2$ cells can then be measured in broncho-alveolar lavage (BAL) or bronchial biopsies. Continuous stimuli may lead to chronic inflammation resulting in severe asthma symptoms including increased mucus secretion, thickening of the airway wall and subsequent narrowing of the airway lumen, inducing shortness of breath, wheeze, cough, and chest tightness ${ }^{15-17}$. Asthma requires treatment with inhaled corticosteroids plus a second controller. Severe forms are treated with systemic corticosteroids and nowadays also monoclonal antibodies that target proinflammatory cytokines $^{18}$. As in other inflammatory diseases, the CXCR4/ CXCL12 axes is involved in asthma pathology: CXCL12 is released in high concentrations into BAL of patients with asthma and correlates with leukocyte infiltration suggesting that it contributes to allergic cell recruitment in asthma ${ }^{19}$. In addition,
CXCR4 expression was shown to be upregulated on eosinophils in the BAL of patients with lung eosinophilia ${ }^{11,20}$ and CXCR4 overexpression on leukocytes is associated with stronger inflammatory processes ${ }^{19,21}$. In mouse models of asthma, targeting CXCR4 with an anti-CXCR4 antibody, or AMD3100, or by neutralizing CXCL12 with inhibiting ligands, reduced eosinophilia and migration of immune cells into the airways, and subsequent release of inflammatory cytokines ${ }^{21-25}$.

CXCR4/CXCL12 also plays a role in inflammatory diseases of the skin, in particular psoriasis, as both molecules are upregulated in inflamed areas of the skin in transgenic mice, as well as human biopsies $^{9,26,27}$. Moreover, treatment with AMD3100 and CXCL12 neutralizing antibodies inhibited skin inflammation in a psoriasis mouse model ${ }^{26}$. However, little is known about the involvement of CXCR4/CXCL12 in atopic dermatitis, a chronically relapsing inflammatory skin disorder with a prevalence of about $1 \%-3 \%$ in adults, and $15 \%-20 \%$ in children, often accompanied by allergic rhinitis, asthma, food allergy, and conjunctivitis ${ }^{28}$. Inflammation is caused by an array of chemokines and adhesion factors that recruit leukocytes to the skin, where they differentiate and become activated by, e.g., dendritic cells, allergens or yet unknown factors ${ }^{29}$. These processes result in disturbed skin barrier function, an elevated and more frequent allergic response, as well as defects in antimicrobial immune defense ${ }^{30}$. Currently, there is no cure for atopic dermatitis. The inflamed skin is treated with topical immunosuppressive corticosteroids and calcineurin inhibitors or, in more severe cases, with oral corticosteroids and dupilumab, a monoclonal antibody that inhibits action of proinflammatory cytokines IL-4 and IL-13 $3^{31}$. However, prolonged therapy with corticosteroids and calcineurin is associated with side effects and antibody therapy is relatively expensive, necessitating the development of new treatment options ${ }^{32}$.

Collectively, these data show that antagonizing CXCR4 is a seminal approach for the treatment of asthma and chronic inflammatory diseases of the skin. One promising novel CXCR4 antagonist is EPI-X4 (endogenous peptide inhibitor of CXCR4) $)^{33-35}$. EPI-X4 is a 16-mer peptide derived from human serum albumin (HSA) originally identified as inhibitor of CXCR4tropic HIV-1 ${ }^{34,37}$. It binds to CXCR4 thereby abrogating binding of CXCL12 and the HIV-1 gp120. Interestingly, EPI-X4 not only antagonized CXCL12-induced CXCR4 signaling but also reduced the basal signaling activity of the receptor in the absence of the 


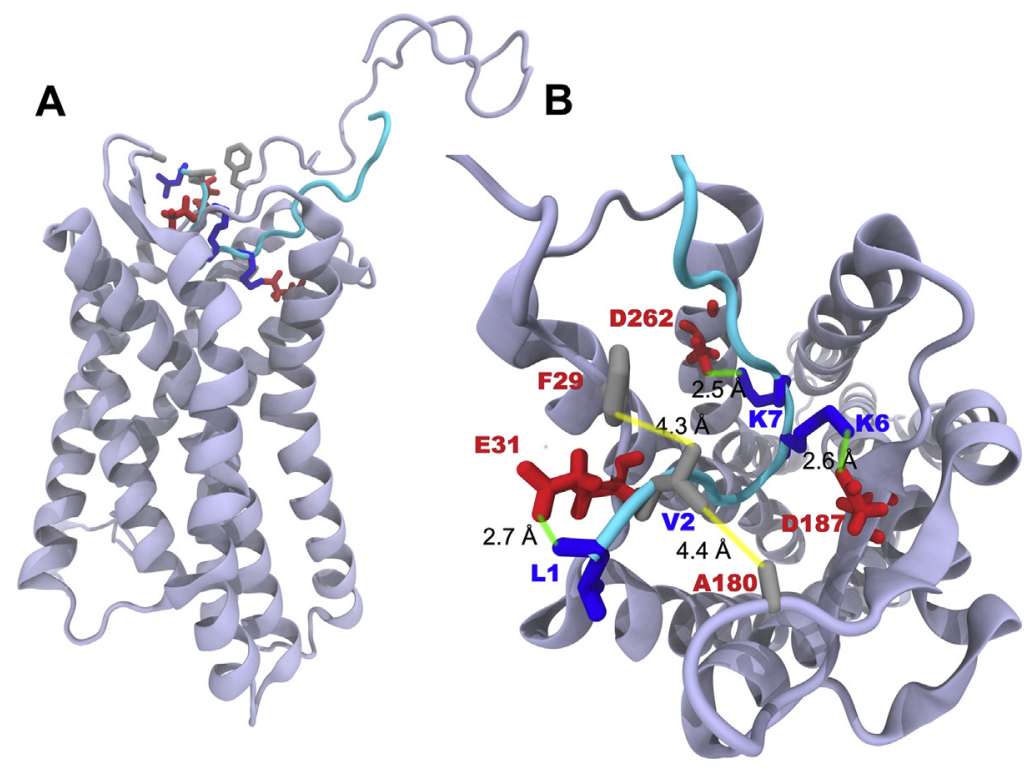

Figure 1 Binding mode of EPI-X4 with CXCR4 obtained by molecular docking. (A) Position of EPI-X4 (cyan) in the binding pocket of CXCR4 (cartoon). (B) Important interactions that stabilize the protein-peptide complex: L1 (N-terminal amine), K6 and K7 of EPI-X4 are involved in salt-bridge interactions (indicated by green lines) with E31, D187 and D262, respectively. Hydrophobic interactions (indicated by yellow lines) are established between V2 of EPI-X4 and F29 and A180 of CXCR4.

chemokine, rendering EPI-X4 also an inverse agonist of CXCR $4^{34}$. The peptide is released from albumin by ubiquitous aspartic proteases, but its physiological function is still unclear ${ }^{36}$. Binding of EPI-X4 to CXCR4 is highly specific as the peptide does not interfere with signaling of other chemokine/chemokine receptor pairs ${ }^{34}$. Furthermore, EPI-X4 was shown to block CXCL12-mediated receptor internalization and suppressed the migration and invasion of cancer and immune cells towards a CXCL12 gradient. Studies in mice provided proof-of concept evidence that EPI-X4 has therapeutic potential since the peptide mobilized hematopoietic stem/progenitor cells and inhibited recruitment of inflammatory immune cells into the lung. However, high concentrations of the endogenous peptide were administered $(\sim 2 \mathrm{mg} \text { EPI-X4 per mouse i.p. })^{33}$. A preliminary structure-activity relationship (SAR) study allowed to increase the CXCR4 blocking activity of EPI-X4 by about 1.5-2 orders of magnitude ${ }^{33}$. We here set out to further optimize the anti-CXCR4 activity of EPI-X4 using rational drug design and to evaluate the therapeutic potential of the lead candidate in mouse models of asthma and atopic dermatitis. We show that the optimized EPI-X4 analog JM\#21 binds CXCR4 with high affinity and antagonizes CXCL12-elicited CXCR4 responses in vitro. Most notably, topical application of EPI-X4 JM\#21 prevented inflammation of the skin and lungs in mouse models of dermatitis and asthma.

\section{Results}

\subsection{Molecular docking of EPI-X4 binding to CXCR4}

Our previous SAR analysis allowed to increase the CXCR4 antagonizing activity of EPI-X4 ( $\mathrm{IC}_{50}$ in the HIV-1 inhibition assay of $\sim 5.9 \mu \mathrm{mol} / \mathrm{L}$ by approximately 23 -fold, resulting in the first-generation lead WSC02 with an $\mathrm{IC}_{50}$ of $254 \mathrm{nmol} / \mathrm{L}$ (Table $\left.1^{33}\right)$. Compared to the parental peptide, the WSC02 analog is Cterminally truncated by four residues and contains four amino acid substitutions (L1I, Y4W, T5S and Q10C). The cysteine at position 10 was introduced to enable dimerization or coupling reactions to linker, fatty acid or other moieties. To further improve the CXCR4 antagonizing activity, we first aimed at obtaining an overview of the interactions of EPI-X4 with the receptor at the molecular level. For this purpose, we modeled the structure of EPI-X4 bound to CXCR4 using molecular docking. The resulting protein-peptide complex shows that EPI-X4 binds in the extracellular pocket of CXCR4 (Fig. 1A). EPI-X4 establishes salt-bridge interactions with negatively charged residues of CXCR4 via the positively charged amino acids L1, K6 and K7. Thus, the positively charged N-terminus (L1) of EPI-X4 interacts with E31 of CXCR4 (Fig. 1B). K6 and K7 form salt-bridges with D187 and D262 of CXCR4, respectively, and the nonpolar amino acid V2 of EPI-X4 establishes hydrophobic contacts with F29 and A180 of CXCR4.

\subsection{Generation of EPI-X4 WSCO2 analogs with increased anti- CXCR4 activity}

The docking model suggests that mutation at position 2 to a slightly longer aliphatic chain (such as V2L) or to a relatively large non-polar sidechain (such as V2F) might improve the hydrophobic contacts between the peptide and the protein. As mentioned above, K6 was also found to be involved in salt-bridge interactions with CXCR4. This supports the hypothesis that changing this amino acid by arginine would increase the binding affinity, since the guanidinium group of arginine can interact strongly with carboxylate groups (via bidentate $\mathrm{H}$-bonds), as compared to the ammonium group. Thus, these and other amino acid substitutions at position 2 and 6 were introduced in WSC02 in order to enhance anti-CXCR4 activity (Fig. 2A and Table 1). The CXCR4 antagonizing activity of this new set of EPI-X4 peptides (JM\#1-JM\#7) was then determined in a CXCR4-tropic HIV-1 infection assay, as described ${ }^{33}$. We used this assay as primary screening test because i) it allows the accurate and fast 
determination of $\mathrm{IC}_{50}$ values, and ii) the anti-HIV-1 activity correlates well with the activity in T-cell migration assays, which are more elaborate ${ }^{33}$. We found, that replacement of the aliphatic and hydrophobic valine (V) at position 2 by leucine (L), harboring a longer functional side-chain (JM\#1), increased the antiviral activity of WSC 02 by 9 -fold $\left(\mathrm{IC}_{50}=27 \mathrm{nmol} / \mathrm{L}\right)$. Substitution by the aromatic phenylalanine $(\mathrm{F})$ had a smaller beneficial effect $\left(\mathrm{JM} \# 2, \mathrm{IC}_{50}=123 \mathrm{nmol} / \mathrm{L}\right)$. Also, the replacement of the positively charged lysine $(\mathrm{K})$ at position 6 by the positively charged arginine (R) increased the activity of WSC02 (JM\#3, $\left.\mathrm{IC}_{50}=166 \mathrm{nmol} / \mathrm{L}\right)$. Replacement of $\mathrm{K} 6$ with the weakly basic amino acid histidine $(\mathrm{H})$, however, had no enhancing effect $\left(\mathrm{JM \# 4}, \mathrm{IC}_{50}=202 \mathrm{nmol} / \mathrm{L}\right)$. Substitution of $\mathrm{V}$ at position 8 by either L (JM\#5) or isoleucine (I, JM\#6) did not significantly alter antiviral activity $\left(\mathrm{IC}_{50}\right.$ values of 241 and $204 \mathrm{nmol} / \mathrm{L}$, respectively). However, substitution with $\mathrm{F}$ increased the anti-HIV-1 activity about 2-fold ( $\mathrm{JM \# 7}, \mathrm{IC}_{50}=119 \mathrm{nmol} / \mathrm{L}$, Fig. 2A and Table 1). Combining beneficial substitutions (JM\#8-JM\#11) resulted in analogs with antiviral activities in the two-digit nanomolar range, with JM\#8 (V2L and K6R) as the most active analog $\left(\mathrm{IC}_{50}=36 \mathrm{nmol} / \mathrm{L}\right.$, Fig. $2 \mathrm{~B}$ and Table 1$)$. Subsequently, based on those findings, additional amino acid substitutions were introduced (JM\#13-JM\#23, Fig. 2C). First, the V at position 8 in JM\#8 was replaced by methionine (M, JM\#13) or L (JM\#21). Those two derivatives were even more active with $\mathrm{IC}_{50}$ values of 16 and $7 \mathrm{nmol} / \mathrm{L}$, respectively. Based on the sequence of JM\#13, V at position 11 was further replaced by either $\mathrm{L}, \mathrm{F}$, or $\mathrm{M}$ (JM\#18-JM\#20) with no beneficial effects. Finally, cysteine (C) 10 in JM\#8 was substituted with non-reactive serine. The resulting $\mathrm{JM} \# 23$ analog was about as active as JM\#8 (42 vs. $36 \mathrm{nmol} / \mathrm{L})$ suggesting that $\mathrm{C} 10$ is not involved in receptor binding (Fig. $2 \mathrm{C}$ and Table 1). EPI-X4 analog JM\#21 consistently blocked HIV-1 infection with the lowest $\mathrm{IC}_{50}$ of $7 \pm 1 \mathrm{nmol} / \mathrm{L}$. Thus, it was selected as lead candidate for further characterization.

\subsection{D NMR-derived solution structure of JM\#21 and WSCO2}

We next analyzed the secondary structures of WSC02 and JM\#21 by NMR. The ten best fitting calculated structures of WSC02 (Fig. 3A) and JM\#21 (Fig. 3B) based on NMR experimental data, have a backbone root-mean-square deviation (RMSD) of $1.16 \pm 0.33$ and $0.83 \pm 0.21$, respectively. WSC02 (Fig. 3C) shows a ring formed by the complete peptide-chain. This ring
Table 1 Structure-activity relationship (SAR) study using WSC02 as a template.

\begin{tabular}{lll}
\hline Compd. & Sequence & $\mathrm{IC}_{50}(\mathrm{nmol} / \mathrm{L})^{\mathrm{a}}$ \\
\hline EPI-X4 & LVRYTKKVPQVSTPTL & $5924 \pm 2490$ \\
WSC02 & IVRWSKKVPCVS & $254 \pm 34$ \\
$\mathrm{JM} \# 1$ & ILRWSKKVPCVS & $27 \pm 10$ \\
$\mathrm{JM} 2$ & IFRWSKKVPCVS & $123 \pm 37$ \\
$\mathrm{JM} \# 3$ & IVRWSRKVPCVS & $166 \pm 26$ \\
$\mathrm{JM} \# 4$ & IVRWSHKVPCVS & $202 \pm 67$ \\
$\mathrm{JM} \# 5$ & IVRWSKKLPCVS & $241 \pm 68$ \\
$\mathrm{JM} \# 6$ & IVRWSKKIPCVS & $204 \pm 22$ \\
$\mathrm{JM} 7$ & IVRWSKKFPCVS & $119 \pm 68$ \\
$\mathrm{JM} \# 8$ & ILRWSRKVPCVS & $36 \pm 18$ \\
$\mathrm{JM} \# 9$ & ILRWSHKVPCVS & $42 \pm 34$ \\
$\mathrm{JM} \# 10$ & IFRWSRKVPCVS & $50 \pm 39$ \\
$\mathrm{JM} \# 11$ & IFRWSHKVPCVS & $69 \pm 64$ \\
$\mathrm{JM} \# 13$ & ILRWSRKMPCVS & $16 \pm 9$ \\
$\mathrm{JM} \# 18$ & ILRWSRKMPCLS & $51 \pm 20$ \\
$\mathrm{JM} \# 19$ & ILRWSRKMPCFS & $55 \pm 12$ \\
$\mathrm{JM} \# 20$ & ILRWSRKMPCMS & $121 \pm 23$ \\
$\mathrm{JM} \# 21$ & ILRWSRKLPCVS & $7 \pm 1$ \\
$\mathrm{JM} \# 23$ & ILRWSRKVPSVS & $42 \pm 8$ \\
\hline
\end{tabular}

${ }^{\mathrm{a}} \mathrm{IC}_{50}$ values shown are means derived from one representative X4-HIV-1 inhibition experiment \pm SEM. IC $_{50}$ values were calculated in GraphPad Prism by non-linear regression; amino acid single letter code is used; amino acid residues labeled in red indicate changes as compared to WSCO2.

involves, in the best fitting state, a hydrogen bond interaction between the sidechains of S12 and W4 (Fig. 3C). Additionally, the carboxylate group of $\mathrm{S} 12$ can form a salt-bridge with the amino group of I1. In contrast, JM\#21 shows a C-terminal loop, which is, again in the best fitting structural state, based on an interaction between the backbone carboxylate of $\mathrm{S} 12$ and the sidechains of R6, K7, L8 and R3, leaving the N-terminus free (Fig. 3E). The fragment W4-S5-R6 exhibits a turn which can be classified as an $\alpha$-turn with four peptide-bonds being involved (Fig. 3D). The superimposition of the two peptides shows that WSC02 and JM\#21 are slightly similar to each other (backbone RMSD $=2.78 \AA$, Fig. 3E), with the main difference that the optimized EPI-X4 JM\#21 contains a flexible N-terminus which might facilitate receptor binding to the extracellular pocket (Fig. 1).

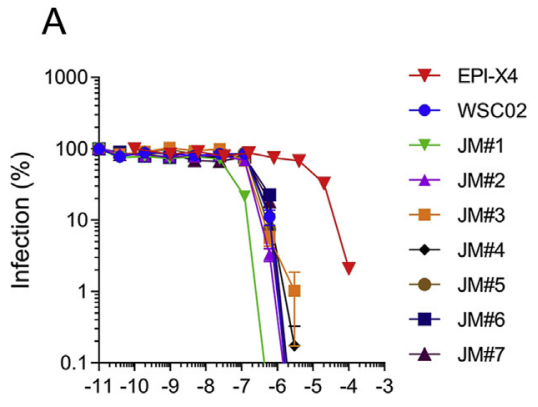

$\log C(\mathrm{~mol} / \mathrm{L})$
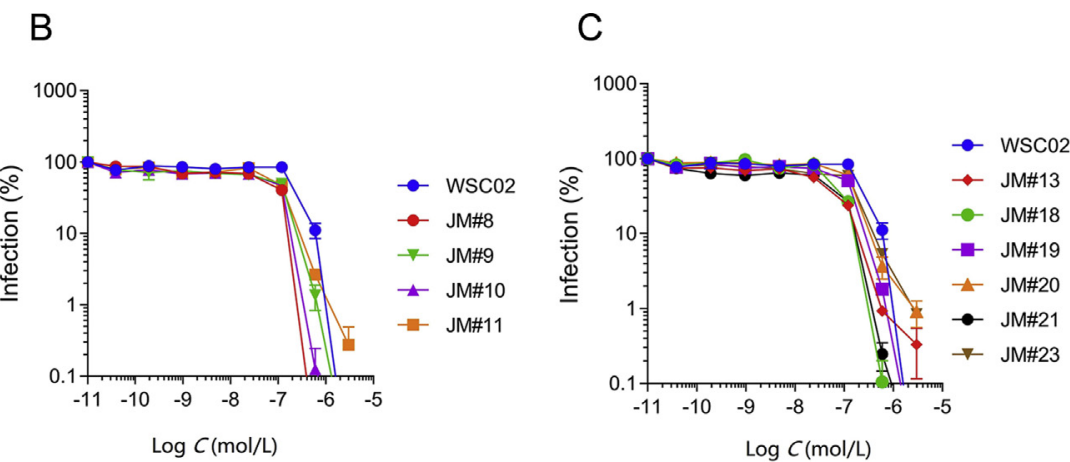

Figure 2 EPI-X4 WSC02 analogues inhibit X4-tropic HIV-1 infection with increased potency. WSC02 derivatives with either a single amino acid substitution (A), two distinct amino acid substitutions (B) or a combination of amino acid substitutions (C) were tested against X4-tropic HIV-1. TZM-bl reporter cells were preincubated with serially diluted peptide and afterwards inoculated with the virus. Infection rates were determined by $\beta$-galactosidase assay 3 days later. Data were represented as mean $\pm \operatorname{SEM}(n=3)$. 


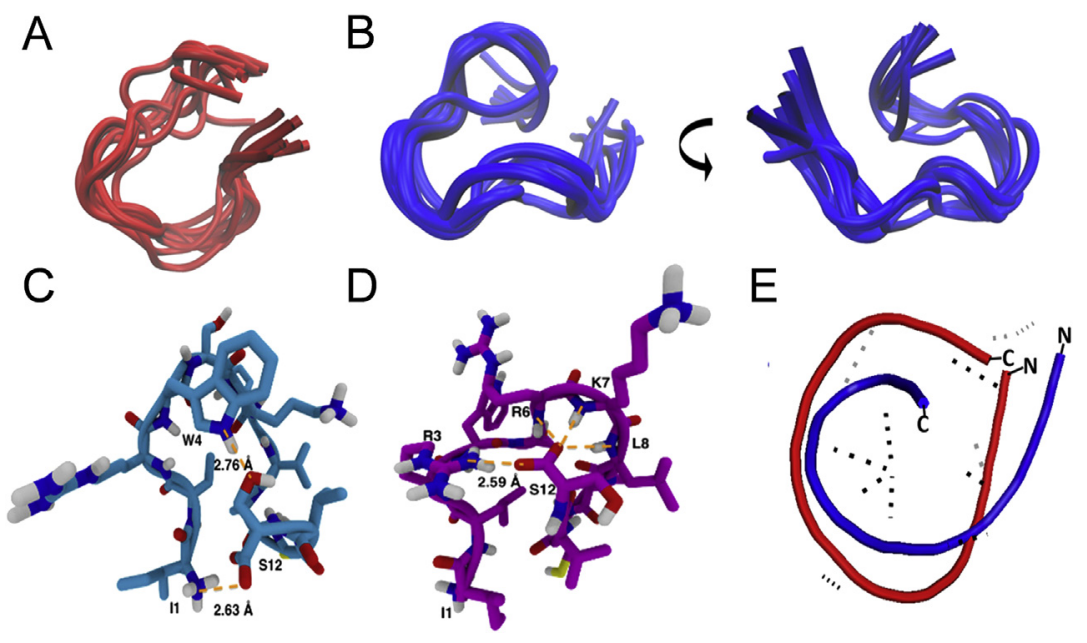

Figure 3 Solution structure of JM\#21 and WSC02. Superimposition of the WSC02 (A) and JM\#21 (B) conformers with the lowest final target function values calculated with ARIA. The visualization was performed with the Molecular Graphics Viewer of Visual Molecular Dynamics $(\mathrm{VMD})^{37}$. (C) and (D) Intramolecular H-bonds in the WSC02 (C) and JM\#21 (D) peptides color code: $\mathrm{C}=$ pink/blue, $\mathrm{H}=$ white, $\mathrm{N}=$ blue, and $\mathrm{O}=$ red. H-bonds are shown as dotted lines in orange. (E) Superimposed structures of WSC02 (red) and JM\#21 (blue).

Next, to compare the putative interactions of EPI-X4 and the optimized derivative with CXCR4, we also performed docking calculations of JM\#21 with CXCR4. We found that residues L2, R6 and L8 of JM\#21 establish favorable interactions with the pocket of CXCR4. L2 of JM\#21 features hydrophobic contacts with F29 at a minimum distance of $3.7 \AA$ (Fig. 4). Notably, the distance between V2 of EPI-X4 and the F29 sidechain (Fig. 1) was larger at $4.3 \AA$. This agrees with our finding that large non-polar amino acids ( $\mathrm{L}$ and $\mathrm{F}$ ) are favored at position 2 (Table 1). Another remarkable difference between JM\#21 and EPI-X4 is given by the introduction of R6 in JM\#21. R6 forms a strong bidentate H-bond with the carboxylate group of D262, compared to the $\mathrm{K} 6_{\mathrm{EPI}-\mathrm{X} 4} / \mathrm{D} 187_{\mathrm{CXCR} 4}$ interaction in the case of EPI-X4. We also note that the presence of large non-polar amino acids (L, I and $\mathrm{F}$ ) at position 8 favors the interaction with the receptor, which is exemplified by the hydrophobic contact between L8 of JM\#21 and I185 of CXCR4. All these interactions may collectively explain the increased activity of JM\#21 with respect to EPI-X4. In addition, we also observed the H-bonding contacts $\mathrm{R} 3_{\mathrm{JM} \# 21} /$ $\mathrm{D} 187_{\mathrm{CXCR} 4}$ and $\mathrm{K} 7_{\mathrm{JM} \# 21} / \mathrm{E} 288_{\mathrm{CXCR} 4}$.

\subsection{EPI-X4 JM\#21 is a potent CXCR4 antagonist}

We next determined binding affinities of EPI-X4 and analogs to CXCR4 using a recently described CXCR4 antibody competition assay $^{38}$. This assay is based on the observation that most if not all CXCR4 antagonists interact with CXCR4 in a way that binding of the CXCR4 12G5 antibody raised against the extracellular loop 2 of the receptor is prevented. As shown in Fig. 5, the first(WSC02) and second-generation (JM\#21) EPI-X4 analogs competed with $12 \mathrm{G} 5$ binding even more efficiently than AMD3100. JM\#21 ( $\left.\mathrm{IC}_{50}=223 \mathrm{nmol} / \mathrm{L}\right)$ was $\sim 2$-fold more active than WSC02 $\left(\mathrm{IC}_{50}=424 \mathrm{nmol} / \mathrm{L}\right)$ and about 3-fold more active than AMD3100 ( $\mathrm{IC}_{50}=687 \mathrm{nmol} / \mathrm{L}$, Table 2). For EPI-X4 an $\mathrm{IC}_{50}$ value of $3.24 \mu \mathrm{mol} / \mathrm{L}$ was determined (Table 2).

Calcium ions $\left(\mathrm{Ca}^{2+}\right)$ are important intracellular messengers since they exert regulatory effects on cytosolic enzymes and proteins and are often induced after CXCR4 activation ${ }^{39}$. Thus, in the next set of experiments, the effect of EPI-X4, its analogs and
AMD3100 on CXCL12-induced intracellular $\mathrm{Ca}^{2+}$ mobilization was analyzed in BCR-ABL transformed bone marrow cells via flow cytometry ${ }^{40}$. As shown in Fig. 6A and B, CXCL12 treatment induced a transient $\mathrm{Ca}^{2+}$ response which was entirely disrupted by $100 \mu \mathrm{mol} / \mathrm{L}$ of the $\mathrm{JM} \# 21$ analog. At the same concentration, WSC02 only suppressed $\mathrm{Ca}^{2+}$ release by $\sim 80 \%$, and EPI-X4 was almost inactive at the tested concentrations (Fig. 6A and B). Here, AMD3100 was more active and reduced $\mathrm{Ca}^{2+}$ mobilization already at a concentration of $1 \mu \mathrm{mol} / \mathrm{L}$, and completely abrogated it at a concentration of $10 \mu \mathrm{mol} / \mathrm{L}$.

CXCL12 binding to CXCR4 also activates the protein kinase $\mathrm{B}$ (PKB, AKT) and extracellular-regulated kinase (ERK) signaling pathways, which are both aberrantly activated in a wide range of human cancers and inflammatory diseases ${ }^{41-43}$. We determined the effect of the CXCR4 antagonists on CXCL12-induced phosphorylation of ERK and AKT in T lymphoblasts by phospho-flow cytometry. JM\#21 potently suppressed CXCL12-induced ERK and AKT phosphorylation with $\mathrm{IC}_{50}$ values of $1.5 \mu \mathrm{mol} / \mathrm{L}$

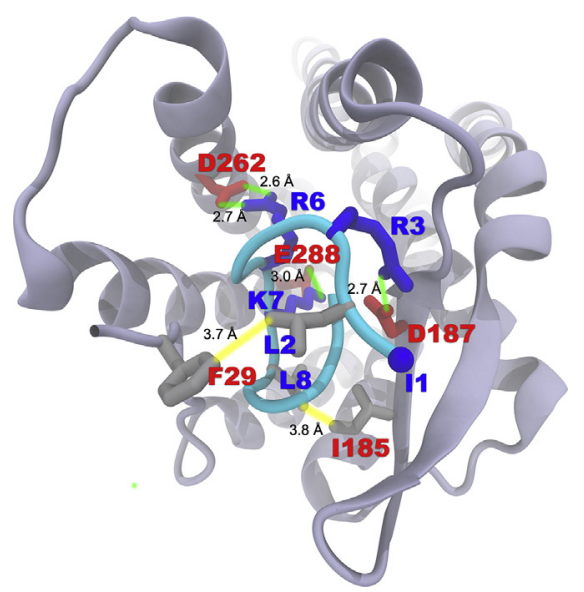

Figure 4 Binding mode of EPI-X4 JM\#21 (cyan) with CXCR4 obtained by molecular docking. The color scheme is the same as in Fig. 1. 
(Fig. 6C) and $2.6 \mu \mathrm{mol} / \mathrm{L}$ (Fig. 6D), respectively (Table 2). AMD3100 was slightly less active compared to JM\#21 for inhibition of ERK phosphorylation (Fig. 6C) and markedly less potent for AKT phosphorylation with $\mathrm{IC}_{50}$ values of 3.3 and $35.0 \mu \mathrm{mol} / \mathrm{L}$, respectively (Fig. 6D and Table 2). EPI-X4 was least active for inhibition of pERK and pAKT (Table 2).

Finally, the four compounds were analyzed for their ability to block migration of the T lymphoblastic lymphoma cell line SupT1 along a CXCL12 gradient. JM\#21 efficiently blocked CXCL12induced cell migration with $\mathrm{IC}_{50}$ values of $0.48 \mu \mathrm{mol} / \mathrm{L}$ (Fig. 7), which was 33-fold more efficient as compared to WSC02 $\left(\mathrm{IC}_{50}=15.8 \mu \mathrm{mol} / \mathrm{L}\right)$ and more than 1400 -fold more efficient than the wild type peptide EPI-X4 $\left(\mathrm{IC}_{50}=681.6 \mu \mathrm{mol} / \mathrm{L}\right)$. In this assay, AMD3100 was most potent with an $\mathrm{IC}_{50}$ of $0.06 \mu \mathrm{mol} / \mathrm{L}$ (Fig. 7 and Table 2).

\subsection{Stability of EPI-X4 JM\#21 in human plasma}

EPI-X4 and EPI-X4 WSC02 have a relatively low proteolytic stability in human and mouse plasma with half-lives of $\sim 17$ and 9 min, respectively ${ }^{33,38}$. Compared to that, AMD3100 was resistant to plasma proteases ${ }^{38}$. To follow up on those results, we determined stability of EPI-X4 JM\#21 in human plasma under identical conditions. JM\#21 exhibits an even lower stability compared to the parental peptides with a half-life of $\sim 6 \mathrm{~min}$ (Fig. 8) arguing for topical or intranasal administration.

\subsection{EPI-X4 JM\#21 shows no toxicity in zebrafish}

Zebrafish embryos provide a useful in vivo system for toxicity assessments of chemicals, since their organs and tissues are similar to those of mammals on the molecular, physiological, and basic anatomical level ${ }^{44}$. To evaluate toxicity, zebrafish embryos were exposed for $24 \mathrm{~h}$ to a maximum of $300 \mu \mathrm{mol} / \mathrm{L}$ of the peptides or controls, and then analyzed in a stereomicroscope for acute toxicity (lethality, necrosis and lysis), developmental toxicity (developmental delay and malformations) and cardiotoxicity (heart edema, reduced or absent circulation). None of the EPI-X4 analogs induced signs of toxicity whereas the membrane damaging antimicrobial peptide pleurodicin $\mathrm{NRCO}^{45}$ was acutely toxic (Fig. 9).

\subsection{EPI-X4 JM\#21 suppresses airway inflammation in a mouse model of allergic airway hypereosinophilia}

It has previously been shown that high doses of EPI-X4 reduce inflammatory cell infiltration in a mouse model of allergic airway

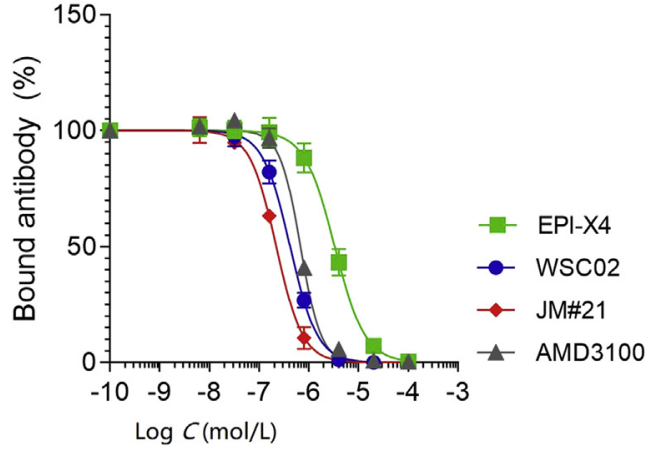

Figure 5 Competition of EPI-X4, WSC02, JM\#21 and AMD3100 with the CXCR4 ECL-2 antibody 12G5. CXCR4 expressing SupT1 cells were precooled and assay buffer was removed. EPI-X4 and the optimized derivatives WSC02 and JM\#21, and the small molecule AMD3100 were diluted in cold PBS and added to the cells. Immediately afterwards, a constant concentration of the APC-labelled CXCR4 antibody (clone 12G5) was added. After $2 \mathrm{~h}$ incubation at $4{ }^{\circ} \mathrm{C}$ unbound antibody was removed and cells analyzed in flow cytometry. Data were represented as mean \pm SEM $(n=3) . \mathrm{IC}_{50}$ values were calculated by non-linear regression.

hypereosinophilia $^{33}$. To examine whether the EPI-X4 derivative JM\#21 may be more potent in preventing airway inflammation, parental EPI-X4 and analogues analogs $(16 \mu \mathrm{mol} / \mathrm{kg}$ body weight $)$ and AMD3100 (12.6 $\mu \mathrm{mol} / \mathrm{kg}$ body weight) were administered intranasally prior to allergen (OVA) challenge. As controls, mice were not challenged with OVA, and solvent only was administered. At day 8, bronchoalveolar lavage was collected and the number of infiltrated cells determined by flow cytometry (Fig. 10A). Allergen challenge resulted in significant infiltration of eosinophils (Fig. 10C), T cells (Fig. 10D), B cells (Fig. 10E) and neutrophils (Fig. 10F), also demonstrated by the total increase in cell count (Fig. 8B), compared to unchallenged control mice. The parental peptide EPI-X4 inhibited the total cell count by $55 \pm 7 \%$ $(P<0.01)$, the recruitment of eosinophils by $76 \pm 7 \%(P<0.01)$, neutrophils by $63 \pm 7 \%(P<0.01)$, T cells by $61 \pm 8 \%$ $(P<0.05)$ and B cells by $54 \pm 9 \%(P<0.05$, Fig. $10 \mathrm{~B}-\mathrm{E})$. The N-terminally truncated version of EPI-X4 (ALB409-423), which does not antagonize CXCR $4^{34}$, did not interfere with most immune cells, but showed a significant activity in blocking neutrophil infiltration, for unknown reasons. Interestingly, the lead candidate JM\#21 was most effective in suppressing migration of immune cells into the airways. Specifically, JM\#21 inhibited the recruitment of eosinophils by $80 \pm 1 \%(P<0.01)$, T cells by

Table 2 Comparison between JM\#21, WSC02, EPI-X4 and AMD3100.

\begin{tabular}{llllll}
\hline Compd. & $\mathrm{IC}_{50} \pm$ SEM $(\mu \mathrm{mol} / \mathrm{L})$ & & & \\
\cline { 2 - 6 } & $125^{\mathrm{a}}$ & $\mathrm{X} 4-\mathrm{HIV}-1^{\mathrm{b}}$ & $\mathrm{pERK}^{\mathrm{c}}$ & $\mathrm{pAKT}^{\mathrm{c}}$ & Migration $^{\mathrm{d}}$ \\
\hline EPI-X4 & $3.24 \pm 0.62$ & $5.924 \pm 2.49$ & $>100$ & $67.60 \pm 30.63$ & $681.63 \pm 305.54$ \\
WSC02 & $0.42 \pm 0.07$ & $0.25 \pm 0.03$ & $15.25 \pm 3.97$ & $37.97 \pm 26.94$ & $15.83 \pm 3.50$ \\
JM\#21 & $0.22 \pm 0.02$ & $0.007 \pm 0.001$ & $1.54 \pm 0.51$ & $2.62 \pm 1.40$ & $0.48 \pm 0.08$ \\
AMD3100 & $0.69 \pm 0.05$ & $0.012 \pm 0.002$ & $3.28 \pm 0.45$ & $35.02 \pm 27.22$ & $0.06 \pm 0.01$ \\
\hline
\end{tabular}

${ }^{\mathrm{a}}$ Competition with the CXCR4 specific 12G5 antibody.

${ }^{\mathrm{b}}$ Inhibition of CXCR4-tropic HIV-1 on TZM-bl cells.

${ }^{\mathrm{c}}$ Inhibition of CXCL12 induced ERK or AKT phosphorylation.

${ }^{\mathrm{d}}$ Inhibition of SupT1 migration towards a CXCL12 gradient. $\mathrm{IC}_{50}$ values are represented as mean \pm SEM $(n=3)$. 
A
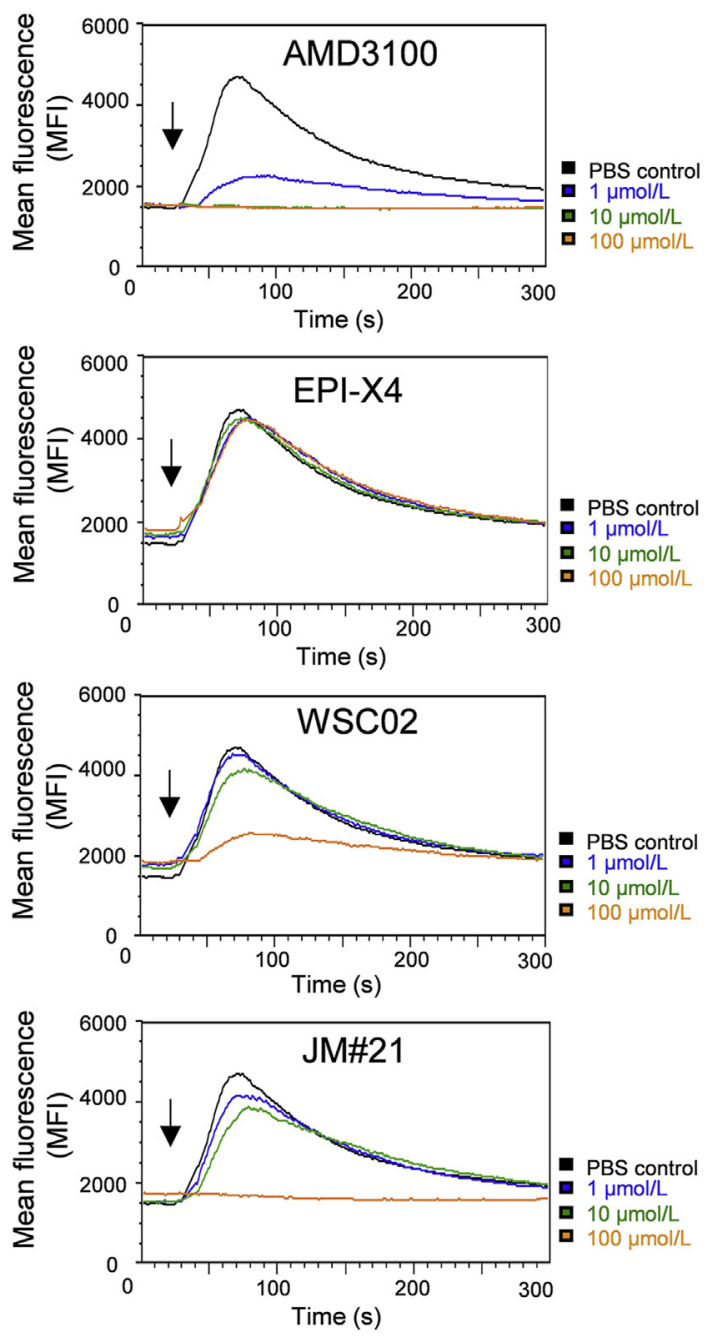

B

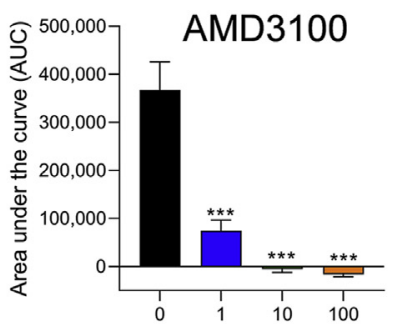

$\log C(\mu \mathrm{mol} / \mathrm{L})$

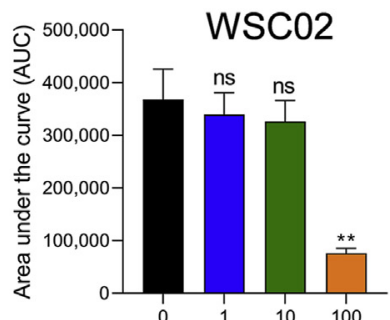

$\log C(\mu \mathrm{mol} / \mathrm{L})$

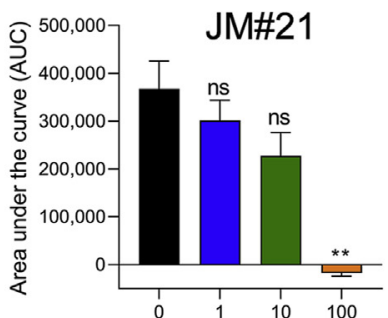

$\log C(\mu \mathrm{mol} / \mathrm{L})$

$\mathrm{D}$

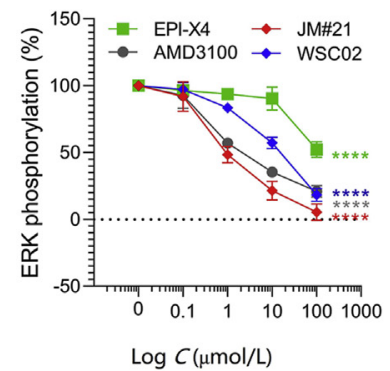

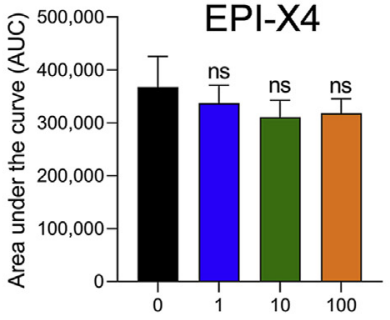

$\log C(\mu \mathrm{mol} / \mathrm{L})$

Figure 6 Effect of EPI-X4 derivatives and AMD3100 on CXCL12-evoked $\mathrm{Ca}^{2+}$ mobilization and ERK and AKT signaling. (A) Inhibition of CXCL12-induced calcium release. BCR-ABL expressing murine pro/pre B cells were loaded with Indo-1 AM and incubated with inhibitors for $10 \mathrm{~min}$. Baseline fluorescence signal was recorded for $30 \mathrm{~s}$ and calcium flux induced by stimulation with $100 \mathrm{ng} / \mathrm{mL} \mathrm{mCXCL} 12$ (black arrow). Signal was recorded for additional $260 \mathrm{~s}$. (B) Areas under the curves (AUC) was calculated after baseline subtraction. Data were represented as mean $\pm \operatorname{SEM}(n=3)$. (C) and (D) Inhibition of CXCL12-induced ERK and AKT phosphorylation. SupT1 cells were preincubated with indicated concentrations of compounds for $15 \mathrm{~min}$ in starvation medium and afterwards stimulated with $100 \mathrm{ng} / \mathrm{mL}$ CXCL12 for 2 min. Cells were then permeabilized and stained for phosphorylated ERK (C) or phosphorylated AKT (D) and analyzed in flow cytometry. Data were represented as mean $\pm \operatorname{SEM}(n=3)$. $\mathrm{IC}_{50}$ values were determined by non-linear regression. $* P<0.05 ; * * P<0.01 ; * * * P<0.001 ; * * * * P>0.0001$; ns $=$ not significant (one-way ANOVA in comparison to PBS control).

$73 \pm 13 \%(P<0.01)$, B cells by $71 \pm 5 \%(P<0.05)$, and neutrophils by $42 \pm 15 \%(P<0.05)$, as well as the total inflammatory cell influx by $61 \pm 12 \%(P<0.01)$ (Fig. $8 \mathrm{~B}-\mathrm{F})$. The control CXCR4 antagonist, AMD3100, also inhibited recruitment of total cells $(41 \pm 13 \%, P<0.05)$, eosinophils $(56 \pm 13 \%$, $P<0.05)$, T cells $(47 \pm 15 \%, P<0.05)$, B cells $(47 \pm 17 \%$, $P<0.05)$ and neutrophils $(57 \pm 14 \%, P<0.05)$, but was on average less active than JM\#21. None of the compounds analysed resulted in infiltration of cells in unchallenged mice. Thus, EPI-X4 JM\#21 is an effective inhibitor of lung inflammation and particularly potent in preventing infiltration of eosinophils, which are believed to play a key role in asthma exacerbations ${ }^{46}$.

\subsection{EPI-X4 JM\#21 prevents skin inflammation in a murine model of atopic dermatitis}

To evaluate the therapeutic potential of EPI-X4 JM\#21 in an inflammatory skin disorder, we tested the peptide in a mouse model of atopic dermatitis. For this, ears of BALB/c mice were treated every 2 days with the vitamin D analog MC903 that induces changes in skin morphology and inflammation resembling immune perturbations observed in acute lesions of patients with $\mathrm{AD}^{47}$. EPI-X4 JM\#21 and reference compounds AMD3100 and dexamethasone were applied topically daily (Fig. 11A). Thickness of ears was measured, and severity of the disease scored daily as 


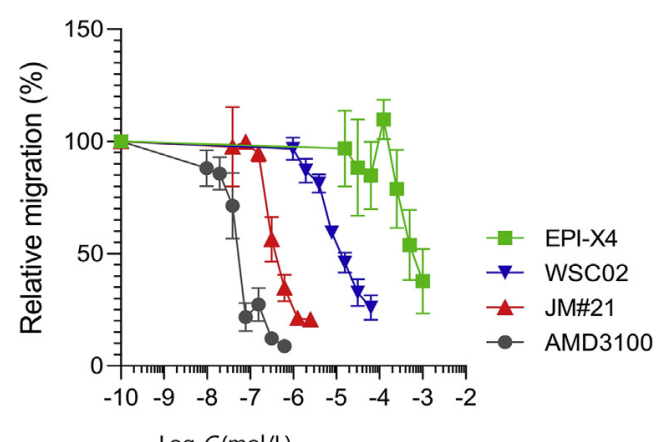

$\log C(\mathrm{~mol} / \mathrm{L})$

Figure 7 Migration of SupT1 cells in the presence of CXCR4 ligands towards a CXCL12 gradient. The assay was performed in a transwell plate with $5 \mu \mathrm{m}$ pore size with $100 \mathrm{ng} / \mathrm{mL}$ CXCL12 in the lower chamber. The number of migrated cells was determined by CellTiterGlo assay. Data were represented as mean $\pm \operatorname{SEM}(n=3)$.

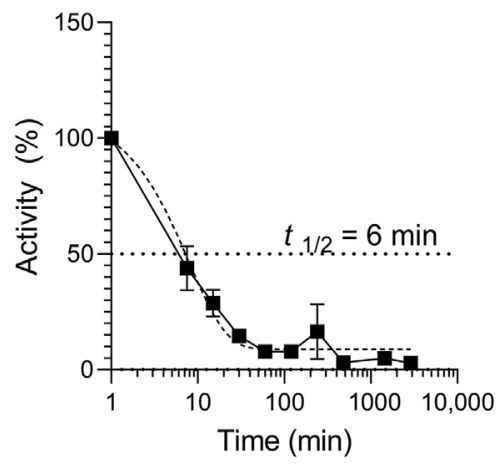

Figure 8 Stability of EPI-X4 JM\#21 in human plasma. $20 \mu \mathrm{mol} / \mathrm{L}$ of EPI-X4 JM\#21 was diluted in $100 \%$ human plasma. The mixture was incubated at $37^{\circ} \mathrm{C}$ and samples taken at indicated time points and stored at $-80^{\circ} \mathrm{C}$. Samples were thawed in parallel, serially diluted in PBS and activity determined by $12 \mathrm{G} 5$-antibody competition. $\mathrm{IC}_{50}$ values were determined by non-linear regression and remaining activity calculated by $\mathrm{IC}_{50}(t=0) / \mathrm{IC}_{50}(t) \times 100$. Data were represented as mean $\pm \operatorname{SEM}(n=3)$.

described in Table 3. None of the compounds induced skin inflammation when administered in the absence of MC903 (Fig. 11B-D). At day 11, MC903 induced a progressive and significant $3.1 \pm 0.1$-fold increase of the ear thickness (Fig. 11B and C), and a high disease score of $9.4 \pm 0.1$ (Fig. 11D) as compared to control $(P<0.0001)$. Treatment of the ears with JM\#21 significantly inhibited ear thickening by $88 \pm 4 \%$ $(P<0.0001)$, and the disease score by $88 \pm 4 \%(P<0.0001)$. Thus, it was almost as effective as dexamethasone $(96 \pm 2 \%$ and $97 \pm 2 \%$, respectively, $P<0.0001$, Fig. 11 B-D). The CXCR4 antagonist AMD3100 had only a minor effect on MC903 induced ear thickness $(25 \pm 7 \%$ inhibition, $P<0.001)$ and disease score (18 $\pm 6 \%$ inhibition, $P<0.001$, Fig. 11 B-D). These results demonstrate that the optimized second-generation CXCR4 antagonist EPI-X4 JM\#21 efficiently inhibits skin inflammation in a mouse model of dermatitis without causing any obvious side effects.

\section{Discussion}

In this study we show that rational drug design allowed to develop an optimized derivative of an endogenous CXCR4 antagonist that effectively prevents inflammatory reactions in murine models of atopic dermatitis and asthma. EPI-X4 JM\#21 differs from WSC02, a first-generation derivative ${ }^{33}$, by three amino acid substitutions. Two exchanges were introduced because molecular docking studies suggested enhanced contacts of the peptide with the extracellular pocket in CXCR4. A third exchange was thought to achieve extra-flexibility of the mid part of EPI-X4 JM\#21. Interestingly, NMR analyses revealed structural differences between $\mathrm{JM \# 21}$ and WSC02, most notably the free N-terminal end in JM\#21. This could explain the superior activity of JM\#21 over WSC02 in cell-based assays, because binding with CXCR4 occurs in a random coil state of the peptide and as the peptide enters the CXCR4 core with its N-terminus (Fig. 1), where a free and accessible N-terminal end could be of advantage. Thus, a combination of empiric and rational drug design allowed to increase the anti-CXCR4 activity of EPI-X4 by nearly three orders of magnitude, as measured in the X4-HIV inhibition assay. EPI-X4 JM\#21 represents the lead of the 2nd generation EPI-X4 derivatives. It inhibited CXCR4 antibody binding and X4-HIV-1 infection, as well as CXCL12-mediated ERK and AKT activation, $\mathrm{Ca}^{2+}$ mobilization and cell migration more efficiently than WSC02. EPI-X4 JM\#21 was also more active than the clinically approved AMD3100, as determined in antibody competition, antiviral and ERK/AKT signaling assays. However, JM\#21 was less active than AMD3100 in cell migration and $\mathrm{Ca}^{2+}$ mobilization assays. The reason(s) for these different activities in
A

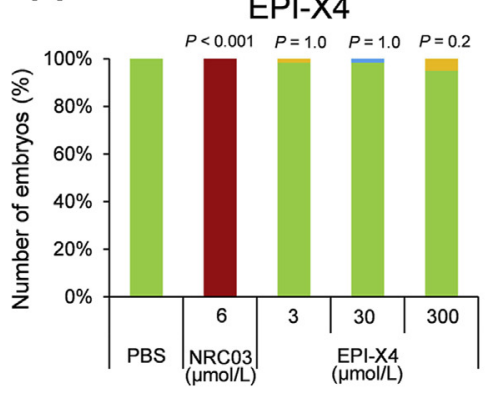

B

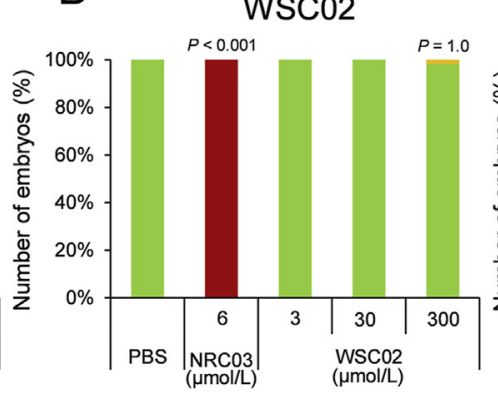

C

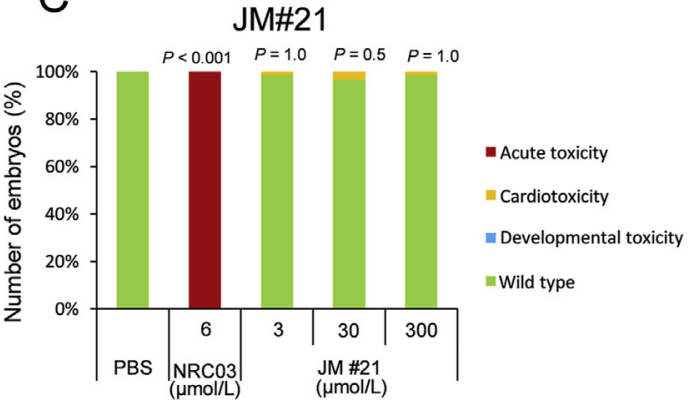

Figure 9 JM\#21 is not toxic in an embryonic zebrafish model. At 24 h post fertilization, dechorionated zebrafish embryos were exposed to EPIX4 (A), WSC02 (B) or JM\#21 (C) for $24 \mathrm{~h}$. As negative control PBS was used, and as positive control the antimicrobial peptide NRC-03. Shown are data derived from 60 embryos per group. 


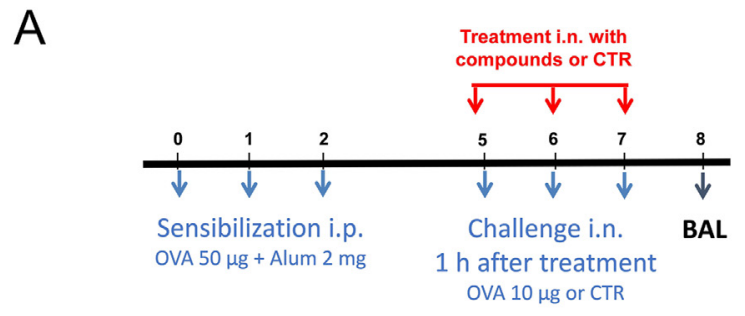

B

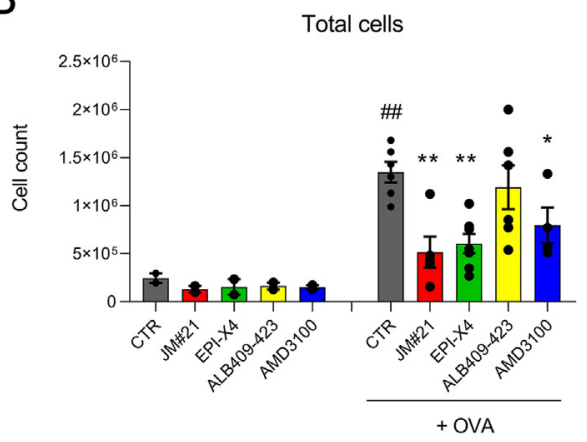

$\mathrm{D}$

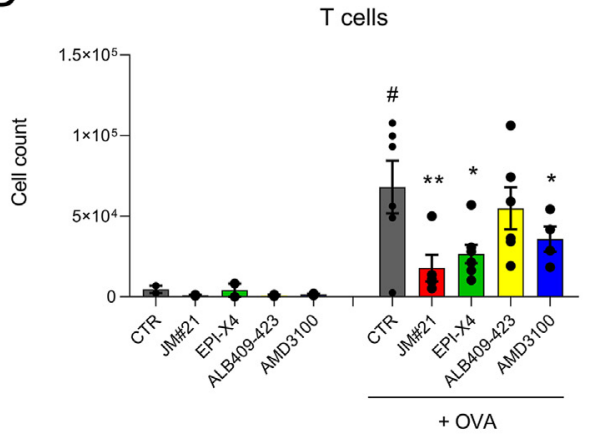

$\mathrm{F}$

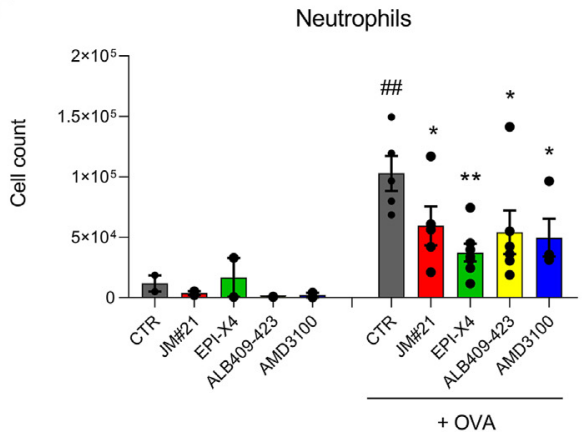

C

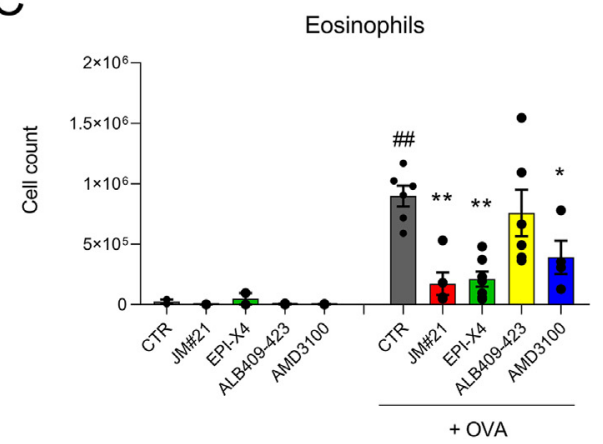

E

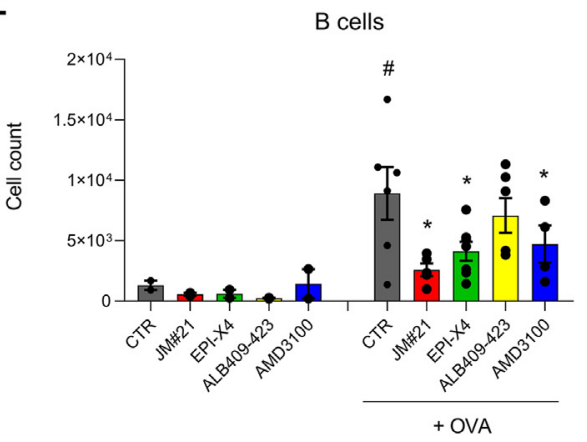

G

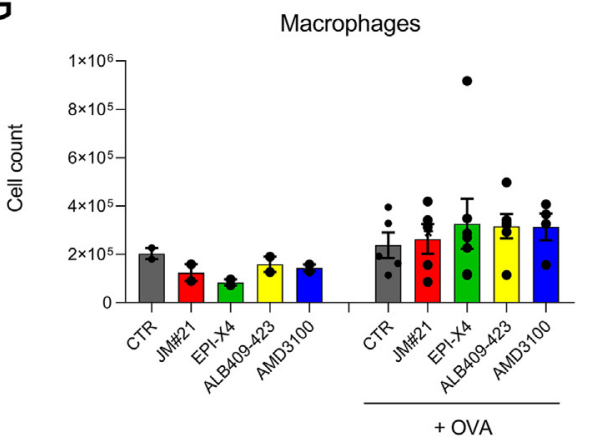

Figure 10 EPI-X4 JM\#21 prevents immune cell infiltration into lungs in a mouse model of airway hypereosinophilia. (A) BALB/c mice were sensitized intraperitoneal (i.p.) with a mixture containing $50 \mu \mathrm{g}$ OVA and $2 \mathrm{mg}$ alum in $0.2 \mathrm{~mL}$ saline on day 0,1 and 2 . Mice were treated by intranasal (i.n.) administration with JM\#21 (16 $\mu \mathrm{mol} / \mathrm{kg})$, EPI-X4 $(16 \mu \mathrm{mol} / \mathrm{kg})$, ALB409-423 (16 $\mu \mathrm{mol} / \mathrm{kg})$ or AMD3100 (12.6 $\mu \mathrm{mol} / \mathrm{kg}), 2 \mathrm{~h}$ before each OVA or saline challenge on Day 5, 6 and 7. Mice were used for OVA-challenged groups $(n=4-6)$ and unchallenged controls $(n=2)$. Number of cells infiltrated into BAL were measured by flow cytometry, (B) all cells; (C) eosinophils; (D) T cells; (E) B cells; (F) neutrophils and $(\mathrm{G})$ macrophages. Data were represented as means $\pm \mathrm{SEM}$. ${ }^{\#} P \leq 0.05,{ }^{\# \#} P \leq 0.01$ compared to unchallenged control group, and $* P \leq 0.05, * * P \leq 0.01$ compared to CTR + OVA group.

antagonizing CXCR4 remain to be determined and may reflect different binding modes of the small molecule AMD3100 versus the JM\#21 peptide to CXCR4. Notably, none of the EPI-X4 derivatives induced acute, cardio- or developmental toxicity in zebrafish embryos, a widely accepted vertebrate model for toxicity assessment. Similarly, we did not observe visible or behavioral adverse effects of EPI-X4, WSC02 or JM\#21 when administered topically onto the ears or intranasally into lungs of mice.

Intranasal application of EPI-X4 and the JM\#21 derivative efficiently reduced influx of various immune and inflammatory cells but not macrophages into BAL in a mouse asthma model. Both peptides were more potent that AMD3100, which has 
A

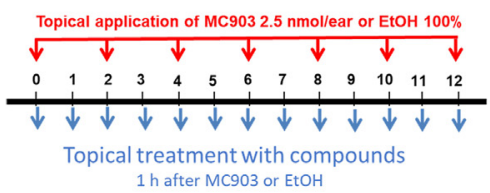

C

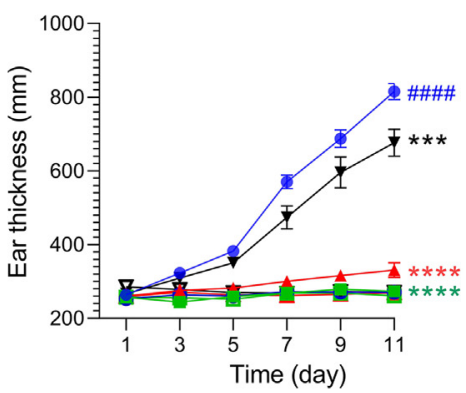

B

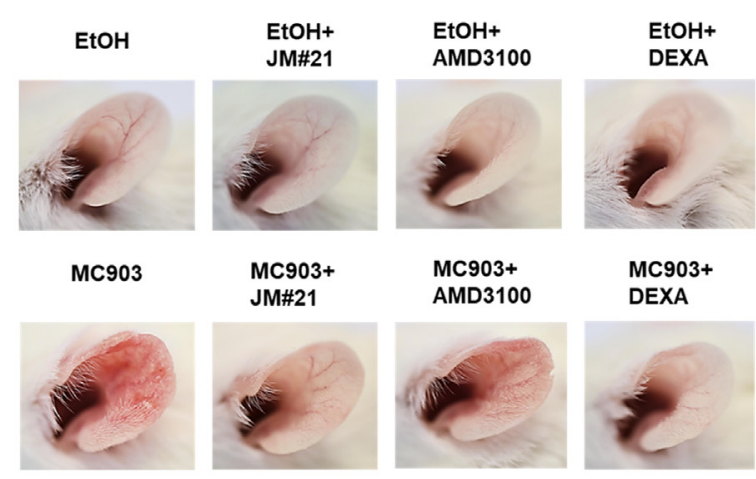

D

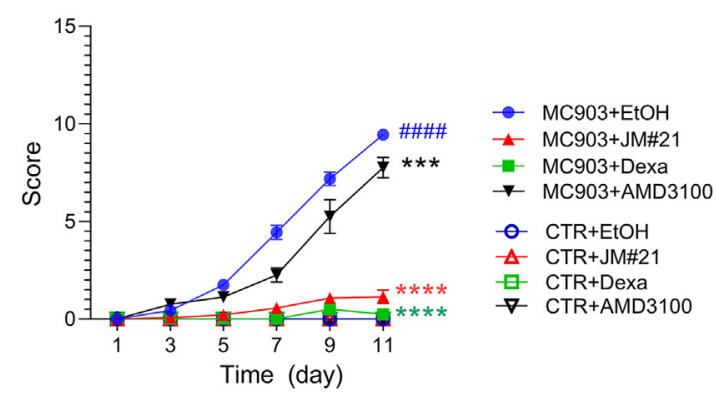

Figure 11 (A) EPI-X4 JM\#21 is active in a mouse model of atopic dermatitis. Ears of BALB/c mice were applied every two days with mock or MC903 (2.5 nmol/ear). (B) EPI-X4 JM\#21 (400 nmol/ear), AMD3100 (315 nmol/ear), dexamethasone (Dexa, $20 \mathrm{nmol} / \mathrm{ear}$ ) or ethanol (EtOH) were applied topically daily. Representative photographs of ears are taken at day 12. Ear thickness (C) and the inflammatory score (D) were

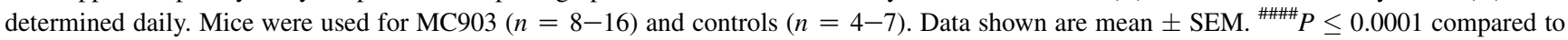
CTR + EtOH group, and $* * * P \leq 0.01, * * * * P \leq 0.0001$ compared to MC903 + EtOH group.

Table 3 Scoring system for atopic dermatitis model.

\begin{tabular}{llllll}
\hline Severity & \multicolumn{4}{l}{ Clinical sign } \\
\cline { 2 - 6 } & \multicolumn{5}{l}{ Redness Blooding Eruption Crusting Sum } \\
\hline Absent & 0 & 0 & 0 & 0 & $0 /$ Score min \\
Mild & 1 & 1 & 1 & 1 & 4 \\
Moderate & 2 & 2 & 2 & 2 & 8 \\
Severe & 3 & 3 & 3 & 3 & $12 /$ Score max \\
\hline
\end{tabular}

previously been shown to attenuate allergen-induced infiltration of inflammatory cells into the airways ${ }^{25,48,49}$. The mechanism(s) underlying CXCR4-mediated inhibition of asthma are not fully understood, but may involve CXCR4-mediated suppression of inflammatory cell (mainly eosinophil) migration ${ }^{21,23,24}$, reduced expression of matrix metalloproteinase MMP-9 that drives airway remodeling $^{48}$, or specific inhibition of CXCR4-expressing neutrophils or eosinophils releasing extracellular traps involved in asthma pathology ${ }^{21,50}$. Eosinophils are main contributors to the development of bronchial asthma and its exacerbations ${ }^{46,50}$. EPI$\mathrm{X} 4$ and the optimized JM\#21 derivative reduced the number of eosinophils in lungs by $76 \pm 7 \%$ and $80 \pm 1 \%$, respectively, suggesting a preferential application of the peptides in eosinophilic asthma. On average, application of $16 \mu \mathrm{mol} / \mathrm{kg}$ EPI-X4 and the optimized JM\#21 analog suppressed inflammatory cell infiltration to a similar extent, which is not reflecting the different activities in antagonizing CXCR4. Perhaps both peptides have been applied at concentrations reaching maximum effects, suggesting that lower doses or less frequent application of JM\#21 may result in similar outcomes, which will be analyzed in advanced preclinical development.

Notably, topical application of EPI-X4 JM\#21 onto the ears effectively reduced skin inflammation in an atopic dermatitis mouse model. To our best knowledge, this is the first report demonstrating that a CXCR4-antagonizing agent shows therapeutic efficacy in an in vivo model of this inflammatory skin disease. Daily treatment with JM\#21 reduced ear thickness and the disease score significantly more efficiently than AMD3100, and almost as efficiently as dexamethasone, an approved corticosteroid. The reason(s) for the differential efficacy of JM\#21 and AMD3100 remain to be addressed. Differences in CXCR4 receptor binding and antagonization, or impaired penetration of AMD3100 into the skin, may be an explanation. It will be interesting to see whether a further increase of the EPI-X4 JM\#21 dose will result in a complete suppression of disease, as shown for dexamethasone. Thus, these findings warrant further development of EPI-X4 JM\#21 as therapeutic agent for atopic dermatitis, especially because the actual continuous treatment of inflamed skin with standard corticosteroids used nowadays is associated with side-effects and novel treatment options are urgently required $^{32}$.

Our findings demonstrate that EPI-X4 and improved derivatives impair inflammatory reactions in mouse models of atopic dermatitis and asthma more efficiently than the FDA-approved 
small molecule AMD3100. It will be interesting to see how EPI$\mathrm{X} 4$ derivatives will perform in comparison to other classes of CXCR4 inhibitors, since several different molecules are currently under pre-clinical development for several different diseases with CXCR4/CXCL12 axis involvement. For EPI-X4 JM\#21, topical treatment of inflamed skin, or intranasal administration in the airway might be an optimal application strategy, since it circumvents problems associated with peptide drugs, e.g., enzymatic instability and rapid excretion. Since, the CXCR4/CXCL12 axis is also involved in other inflammatory diseases of skin and lungs (e.g., psoriasis ${ }^{26}$, and pulmonary fibrosis ${ }^{51,52}$ ), EPI-X4 JM\#21 should also be evaluated as therapeutic agent for these disorders. In contrast to AMD3100, that is known for severe side effects after continued treatment and is therefore not approved for chronic diseases ${ }^{14}$, a peptide drug based on the body-own EPI-X4 will also most likely be well tolerated. Thus, further preclinical and clinical development of JM\#21 as a novel class of CXCR4 inhibitors is highly warranted.

\section{Experimental}

\subsection{Molecular modeling}

The reported crystal structure of CXCR4 (PDB ID: 3ODU) was used for the modelling studies ${ }^{53}$. The missing N-terminal loop was added using the NMR structure of the N-terminus of CXCR4 (PDB ID: 2K04) ${ }^{54}$. The NMR structures of EPI-X4 (PDB ID: $2 \mathrm{NOX})^{33}$ and of JM\#21 (reported here) were used for the docking studies with CXCR4. The molecular docking calculations were carried out using the HADDOCK v2.2 webserver available at http://www.bonvinlab.org/software/haddock $2.2 /^{55,56}$.

\subsection{Reagents and peptide synthesis}

All chemicals were used as provided by the manufacturers. Amino acids were purchased from Novabiochem (Merck KGaA, Darmstadt, Germany). N,N-dimethylformamide (DMF), 20\% ( $v / v)$ piperidine in DMF, $O$-benzotriazole- $N, N, N^{\prime}, N^{\prime}$-tetramethyluronium-hexafluoro-phosphate (HBTU) and trifluoroacetic acid (TFA) were purchased from Merck Millipore (Merck KGaA). Triisopropylsilane (TIS), diisopropylethylamine (DIEA) were purchased from Sigma-Aldrich (Sigma-Aldrich Chemie GmbH Munich, Germany). Acetonitrile was purchased from JT.Baker (Avantor Performance Materials B.V. 7418 AM Deventer Netherlands). The peptides were synthesized automatically on a 0.10 mmol scale using standard Fmoc solid phase peptide synthesis techniques with the microwave synthesizer (Liberty blue; CEM). A preloaded resin was used and provided in the reactor. The resin was washed with DMF. The Fmoc protecting group was removed with $20 \%(v / v)$ piperidine in DMF and initialized with microwave followed by washing with DMF. Amino acids were added in $0.2 \mathrm{~mol} / \mathrm{L}$ equivalent to the reactor, then HBTU in a $0.5 \mathrm{~mol} / \mathrm{L}$ equivalent was dosed to the amino acid solution. After that, $2 \mathrm{~mol} / \mathrm{L}$ equivalent of DIEA was added to the resin. The coupling reaction was proceeded with microwaves for a few minutes then the resin was washed in DMF. These steps were repeated for all amino acids in the sequence. The last amino acid was deprotected. Once the synthesis was completed, the peptide was cleaved in $95 \%(v / v)$ trifluoroacetic acid (TFA), $2.5 \%(v / v)$ triisopropylsilane (TIS), and $2.5 \%(v / v) \mathrm{H}_{2} \mathrm{O}$ for $1 \mathrm{~h}$. The peptide residue was precipitated and washed with cold diethyl ether (DEE) by centrifugation. The peptide precipitate was then allowed to dry under air flow to remove residual ether. The peptide was purified using reversed phase preparative high-performance liquid chromatography (HPLC; Waters) in an acetonitrile/water gradient under acidic conditions on a Phenomenex C18 Luna column (5 mm pore size, $100 \AA$ particle size, $250 \mathrm{~mm} \times 21.2 \mathrm{~mm}$ ). Following purification, the peptide was lyophilized on a freeze dryer (Labconco) for storage prior to use. The purified peptide mass was verified by liquid chromatography mass spectroscopy (LCMS; Waters). AMD3100 octahydrochloride hydrate was purchased from Sigma-Aldrich (\#A5602) and dissolved in $\mathrm{H}_{2} \mathrm{O}$. CXCL12 was purchased from Peprotech (\#300-28A) and dissolved at a concentration of $100 \mu \mathrm{g} / \mathrm{mL}$ in $\mathrm{H}_{2} \mathrm{O}$. Information about purities, yields and structural identification spectra are provided in the supplement.

\subsection{Nuclear magnetic resonance spectroscopy}

Nuclear magnetic resonance spectra were collected on a Bruker $700 \mathrm{MHz}$ AvanceIII spectrometer with a $5 \mathrm{~mm} \mathrm{BBI}{ }^{1} \mathrm{H} / \mathrm{BB}$ probe equipped with a $z$-gradient and on a $850 \mathrm{MHz}$ AVANCE III system equipped with a $5 \mathrm{~mm}$ triple resonance TXI ${ }^{1} \mathrm{H} /{ }^{13} \mathrm{C} /{ }^{15} \mathrm{~N}$ probe with a z-gradient at $298 \mathrm{~K}$. NMR samples with JM\#21 or WSC02 were prepared with $5 \mathrm{mg}$ peptide each in $500 \mu \mathrm{L}$ MilliQ-water containing $10 \%(v / v) \mathrm{D}_{2} \mathrm{O}$. Several homo- and hetero-nuclear 2D NMR spectra (HSQC, HMBC, COSY, TOCSY, and NOESY) were recorded for the assignment of the ${ }^{1} \mathrm{H}$ and ${ }^{13} \mathrm{C}$ resonances at natural isotope abundance. NMR spectra were processed using Topspin 3.6 and were analyzed using NMRFAMSPARKY $^{55}$. After manual peak assignment and extraction of the peak intensities, the data was incorporated into the program ARIA for structure calculations ${ }^{57}$.

\subsection{Cell culture}

TZM-bl HIV-1 reporter cells stably expressing CD4, CXCR4 and CCR5 and harboring the lacZ reporter genes under the control of the HIV LTR promoter were obtained through the NIH AIDS Reagent Program, Division of AIDS, NIAID, NIH: TZM-bl cells (Cat\#8129) from Dr. John C. Kappes, and Dr. Xiaoyun Wu. TZMbl cells and HEK293T cells were cultured in DMEM supplemented with $10 \%$ fetal calf serum (FCS), 100 units/mL penicillin, $100 \mu \mathrm{g} / \mathrm{mL}$ streptomycin, and $2 \mathrm{mmol} / \mathrm{L} \mathrm{L}$-glutamine (Gibco). SupT1 cells were cultured in RPMI supplemented with $10 \%$ FCS, 100 units $/ \mathrm{mL}$ penicillin, $100 \mu \mathrm{g} / \mathrm{mL}$ streptomycin, $2 \mathrm{mmol} / \mathrm{L} \mathrm{L}-$ glutamine and $1 \mathrm{mmol} / \mathrm{L}$ HEPES (Gibco). The BCR-ABL cell line was generated introducing the BCR-ABL expression vector into bone marrow-derived wild type pro/pre B cells. Cells were cultured in Iscove's basal medium supplemented with $10 \%$ FCS, $100 \mathrm{U} / \mathrm{mL}$ penicillin, $100 \mathrm{U} / \mathrm{mL}$ streptomycin, $2 \mathrm{mmol} / \mathrm{L} \mathrm{L}$ glutamine and $50 \mu \mathrm{mol} / \mathrm{L} \beta$-mercaptoethanol.

\subsection{HIV-1 inhibition assay}

Viral stocks of CXCR4-tropic NL4-3 were generated by transient transfection of HEK293T cells with proviral DNA as described before $^{33}$. Inhibition of viral infection was performed in TZM-bl reporter cells. For this $70 \mu \mathrm{L}$ of $1 \times 10^{5}$ cells (in growth medium supplemented with $2.5 \%$ FCS) were pretreated with $10 \mu \mathrm{L}$ of inhibitors for $15 \mathrm{~min}$ at $37^{\circ} \mathrm{C}$. Cells were then inoculated with $20 \mu \mathrm{L}$ of diluted virus. Infection rates were determined after 3 days using Gal-Screen system (Applied Biosystems). 


\section{6. $\mathrm{Ca}^{2+}$ mobilization assay}

A well-established murine cell line expressing the fusion protein BCR-ABL was used for the experiments. Measurement of intracellular calcium flux was performed as described previously ${ }^{58}$. $1 \times 10^{6}$ cells were incubated with $5 \mu \mathrm{g} / \mathrm{mL}$ of Indo- $1 \mathrm{AM}$ (Invitrogen) and $0.5 \mu \mathrm{g} / \mathrm{mL}$ of pluronic F-127 (Invitrogen) in Iscove's medium supplemented with $1 \%$ FCS (Pan Biotech) at $37{ }^{\circ} \mathrm{C}$ for $45 \mathrm{~min}$. Cells were then pelleted by centrifugation and resuspended in Iscove's medium with $1 \%$ FCS and treated with the EPI-X4 derivatives for $10 \mathrm{~min}$ at $37{ }^{\circ} \mathrm{C}$. Prior measurement cells were pre-warmed for $5 \mathrm{~min}$ at $37{ }^{\circ} \mathrm{C}$. Calcium flux was assessed by FACS measurement at BD LSR Fortessa. After $30 \mathrm{~s}$ of baseline recording, CXCR4-dependent calcium signaling was determined by stimulating with $100 \mathrm{ng} / \mathrm{mL}$ of mouse SDF- $1 \alpha$ (PeproTech). To quantify CXCL12-induced $\mathrm{Ca}^{2+}$ mobilization, the kinetics analysis platform of FlowJo analysis software (BD Biosciences) was used to determine the area under the curve (AUC) of each calcium flux plot. In order to allow for interexperimental comparison, the AUC was calculated after baseline subtraction for each single plot. AUC values were exported from FlowJo into MS-Excel where calculations were performed. Statistical analysis was performed using GraphPad Prism 8. One-way ANOVA with Tukey's multiple comparisons test was performed. Degree of significance is indicated as follows: ${ }^{*} P<0.05$; ${ }^{*} P<0.01 ;{ }^{* * *} P<0.001 ; \mathrm{ns}=$ not significant.

\subsection{ERK and AKT signaling}

CXCL12 induced phosphorylation of ERK and AKT was monitored by phosphoflow cytometry as described before ${ }^{38}$. For this 100,000 SupT1 cells were starved for $2 \mathrm{~h}$ at $37{ }^{\circ} \mathrm{C}$ (growth medium supplemented with $1 \%$ FCS). Inhibitors were then added for $10 \mathrm{~min}$ and cells subsequently stimulated with $100 \mathrm{ng} / \mathrm{mL}$ CXCL12 for $2 \mathrm{~min}$. The reaction was stopped by adding 1\% PFA and shifting to $4{ }^{\circ} \mathrm{C}$ for at least $10 \mathrm{~min}$. Cells were then permeabilized with ice cold methanol and stained with phospho-p44/ 42 MAPK (ERK1) (Tyr204)/(ERK2) (Tyr187) (D1H6G) mouse $\mathrm{mAb}$ (Cell Signaling, \#5726) and phospho-AKT (Ser473) (193H12) rabbit mAb (Cell Signaling, \#4058) and adequate secondary antibodies for flow cytometry. Signal in the unstimulated control without inhibitor was defined as background and set to $0 \%$. CXCL12 induced signal without inhibitor was set $100 \%$.

\subsection{Cell migration assay}

Migration assays towards a $100 \mathrm{ng} / \mathrm{mL}$ CXCL12 gradient were performed with SupT1 cells using 96-well transwell assay plates (Corning Incorporated, Kennebunk, ME, USA) with $5 \mu \mathrm{m}$ polycarbonate filters. First, $50 \mu \mathrm{L}\left(0.75 \times 10^{5}\right)$ SupT1 cells resuspended in assay buffer (RPMI supplemented with $0.1 \%$ BSA) were seeded into the upper chamber in the presence or absence of compounds and allowed to settle down for around $15 \mathrm{~min}$. In the meantime, $200 \mu \mathrm{L}$ assay buffer supplemented with or without $100 \mathrm{ng} / \mathrm{mL}$ CXCL12 as well as compounds were filled into a 96 well-V plate. Cells were allowed to migrate towards CXCL12 by putting upper chamber onto the 96 well-V plate. After a migration time of $4 \mathrm{~h}$ at $37{ }^{\circ} \mathrm{C}\left(5 \% \mathrm{CO}_{2}\right)$ lower compartment were analyzed for cell content by Cell-Titer-Glo® assay (Promega, Madison, WI, USA). Percentages of migrated cells were calculated as described before $^{59}$ and normalized to the CXCL12-only control.

\subsection{Antibody competition assay}

Competition with the ECL-2 specific CXCR4 antibody was performed as described before ${ }^{38}$. Compounds were serially diluted in cold PBS and afterwards added to 50,000 SupT1 cells. APCconjugated anti-human CXCR4 antibody (clone 12G5, \#555976, BD) was diluted in PBS containing 1\% FCS and added immediately afterwards at a final concentration of $0.245 \mathrm{nmol} / \mathrm{L}$. After $2 \mathrm{~h}$ incubation at $4{ }^{\circ} \mathrm{C}$, unbound antibody was removed and cells analyzed in flow cytometry.

\subsection{Toxicity in zebrafish}

Wild-type zebrafish embryos were dechorionated at $24 \mathrm{~h}$ post fertilization (hpf) using digestion with $1 \mathrm{mg} / \mathrm{mL}$ pronase (Sigma) in $\mathrm{E} 3$ medium $(83 \mu \mathrm{mol} / \mathrm{L} \mathrm{NaCl}, 2.8 \mu \mathrm{mol} / \mathrm{L} \mathrm{KCl}, 5.5 \mu \mathrm{mol} / \mathrm{L}$ $\mathrm{CaCl}_{2}, 5.5 \mu \mathrm{mol} / \mathrm{L} \mathrm{MgSO}_{4}$ ). Embryos were exposed for $24 \mathrm{~h}$ in groups of 3-100 $\mu \mathrm{L}$ of E3 containing the test substances. Peptides were tested at 3, 30 and $300 \mu \mathrm{mol} / \mathrm{L}$. Each concentration was tested in two independent assays, each of which was performed on $10 \times 3$ embryos. The peptide solvent (PBS), diluted in E3, was used as negative control at the same amount as introduced by the highest peptide concentration. As positive control for acute toxicity the pleurocidin antimicrobial peptide NRC-03 (GRRKRKWLRRIGKGVKIIGGAALDHL-NH $\mathrm{N}_{2}$ ) was used at a concentration of $6 \mu \mathrm{mol} / \mathrm{L}^{45}$. At $48 \mathrm{hpf}$ (after $24 \mathrm{~h}$ of incubation) embryos were scored in a stereomicroscope for signs of acute toxicity (lysis and/or necrosis), developmental toxicity (delay and/ or malformations), or cardiotoxicity (heart edema and/or reduced or absent circulation). Chi-Square test was used to calculate whether the distribution of embryos into toxicity classes differed significantly between the PBS negative control and the test substances.

\subsection{Mice}

Nine-week-old male BALB/c mice (Janvier, France) were used. The animals were maintained on a 12/12-h light/dark cycle, with food and water ad libitum. All animals received humane care in compliance with the guidelines formulated by the French Ministry of Agriculture and of Higher Education and Research, who authorized the procedures (APAFiS \#10067 and \#1341).

\subsection{Effect of EPI-X4 JM\#21 in a mouse model of atopic dermatitis}

Mice were anesthetized by isoflurane 5\% (Dechra) before each topical application. MC903 (calcipotriol hydrate, Sigma) was dissolved in $\mathrm{EtOH} 100 \%$ and topically applied at $2.5 \mathrm{nmol} / \mathrm{ear}$ every two days from day 0 to day 12 on both sides of the mouse ears. EtOH $100 \%$ was applied to control mice every two days. All peptides were solubilized in $\mathrm{EtOH} 80 \%$ and applied topically at $400 \mathrm{nmol} / \mathrm{ear}(=16 \mu \mathrm{mol} / \mathrm{kg} / \mathrm{ear})$ in a volume of $25 \mu \mathrm{L} /$ ear every day from day 0 to day $12,1 \mathrm{~h}$ after MC903 application. Reference compound dexamethasone (Dexa, Sigma) was also used topically and daily at $20 \mathrm{nmol} / \mathrm{ear}(=0.8 \mu \mathrm{mol} / \mathrm{kg} / \mathrm{ear})$ and dissolved in EtOH $80 \%$. The reference CXCR4 non peptidic antagonist AMD3100 (Euromedex) was used daily, topically at $315 \mathrm{nmol} / \mathrm{ear}$ $(=12.6 \mu \mathrm{mol} / \mathrm{kg} / \mathrm{ear})$ and dissolved in $\mathrm{EtOH} 80 \%$. Ear thickness was measured with a digital micrometer every day before the next topical application, and a mean value of the measurements of both 
ears was calculated. Scores were registered daily to evaluate the severity of the atopic dermatitis, following the scoring system on Table 3. Photographs of the ears were taken at day 12 .

\subsection{Effect of EPI-X4 JM\#21 in a mouse model of allergic airway hypereosinophilia}

Mice were sensitized by intraperitoneal (i.p.) injection of a mixture containing $50 \mu \mathrm{g}$ ovalbumin (OVA, grade V, Sigma) and $2 \mathrm{mg} \mathrm{Al}(\mathrm{OH})_{3}$ (alum, Sigma) in saline on day 0, 1 and 2. On day 5 , 6 and 7 , mice were treated with peptides $(16 \mu \mathrm{mol} / \mathrm{kg})$, AMD3100 (12.6 $\mu \mathrm{mol} / \mathrm{kg}$, Euromedex) or solvent ( $\mathrm{NaCl} 0.9 \%)$ by intranasal administration (i.n., $12.5 \mu \mathrm{L} /$ nostril). Two hours later, mice were challenged i.n. with $10 \mu \mathrm{g}$ of OVA in saline. The unchallenged controls were administered i.n. with saline. Before each intranasal administration, mice were anesthetized with ketamine $(75 \mathrm{mg} / \mathrm{kg}$, Merial) and xylazine $(5 \mathrm{mg} / \mathrm{kg}$, Bayer $)$. Mice were kept on a hot plate $\left(37{ }^{\circ} \mathrm{C}\right)$ until complete awakening. On day 8 , mice were anesthetized with ketamine $(300 \mathrm{mg} / \mathrm{kg}$, Merial) and xylazine $(20 \mathrm{mg} / \mathrm{kg}$, Bayer) and bronchoalveolar lavage performed with PBS-EDTA $2 \mathrm{mmol} / \mathrm{L}^{23}$. Briefly, a catheter was inserted into the trachea, and lungs were washed 10 times with $500 \mu \mathrm{L}$ of PBS-EDTA $2 \mathrm{mmol} / \mathrm{L}$. BAL fluid was centrifuged $\left(300 \times g\right.$ for $5 \mathrm{~min}, 4^{\circ} \mathrm{C}$ ), cell pellet suspended in $500 \mu \mathrm{L}$ of PBSEDTA and total cells counted on a Muse Cell Analyser (Millipore) using anti-CD45-PE antibody (eBioscience, 1:500). Differential cell counts were assessed by flow cytometry (LSRII ${ }^{\circledR}$ cytometer, BD Bioscience). BAL cells were added with Fc Block (BD Bioscience) for $20 \mathrm{~min}$ and then marker antibodies were incubated for 30 min: CD11c-FITC (BD Bioscience, 1:250), GR-1-PEeFluor610 (eBioscience, 1:500), CD11b-APC-Cy7 (BD Bioscience, 1:200), CD45-AlexaFluor700 BioLegend, 1:200), CD3BV650 (BD Bioscience, 1:250), CD19-BV605 (BD Bioscience, 1:250), DAPI (BD Bioscience, 1:500). Live leukocytes were identified as $\mathrm{CD}^{2} 5^{+} \mathrm{DAPI}^{-}$cells then differentiated into $\mathrm{T}$ cells $\left(\mathrm{CD} 11 \mathrm{~b}^{\text {low }} \mathrm{CD} 19^{-} \mathrm{CD}^{+}\right)$, B cells $\left(\mathrm{CD} 11 \mathrm{~b}^{\text {low }} \mathrm{CD} 19^{+} \mathrm{CD} 3^{-}\right)$, eosinophils $\quad\left(\mathrm{CD} 11 \mathrm{~b}^{+} \mathrm{CD} 11 \mathrm{c}^{-} \mathrm{GR} 1^{-}\right), \quad$ neutrophils $\left(\mathrm{CD} 11 \mathrm{~b}^{+} \mathrm{CD} 11 \mathrm{c}^{-} \mathrm{GR} 1^{+}\right)$and macrophages $\left(\mathrm{CD} 11 \mathrm{~b}^{+} \mathrm{GR} 1^{-} \mathrm{CD} 11 \mathrm{c}^{+}\right)$.

\subsection{Calculations and statistical analysis}

Statistical analysis was performed in GraphPad Prism (version 8.3.0). $\mathrm{IC}_{50}$ curves were determined by nonlinear regression. Differences between groups were tested for statistical significance using a one-way ANOVA followed by Bonferroni's post-test. Data were considered significantly different when $P \leq 0.05$.

\section{Acknowledgments}

This work was supported by the German Research Foundation (DFG) through the CRC1279 to Ludger Ständker, Gönül Kizilsavas, Elsa Sanchez-Garcia, Manfred Wagner, Gilbert Weidinger, Frank Kirchhoff and Jan Münch, the DFG by individual grants (MU 3115/11-1 and MU 3115(8-1)) to Jan Münch, the BadenWürttemberg Stiftung to Jan Münch, and an ERC-PoC grant "EPIX4 Health" to Frank Kirchhoff and Jan Münch. Elsa SanchezGarcia was also supported by the DFG under Germany's Excellence Strategy-EXC 2033-390677874-RESOLV and by the Boehringer Ingelheim Foundation (Plus-3 Program).

\section{Author contributions}

Pandian Sokkar, Sara Carmignani and Elsa Sanchez-Garcia did the computational docking analysis. Mirja Harms, Monica Habib and Ashraf H. Abadi did the rational drug design and peptides were synthesized by Nico Preising and Ludger Ständker, Monica Habib contributed in the peptides' synthesis, purification and identification, Mirja Harms did most of the in vitro experiments, except for the $\mathrm{Ca}^{2+}$ release experiments that were done by Antonella Nicolò and Hassan Jumaa, and the migration experiment that was performed by Andrea Gilg. Gönül Kizilsavas and Manfred Wagner determined all NRM structures. Martina Raasholm. and Gilbert Weidinger performed the zebrafish toxicity assay, and Simona Nemska and Nelly Frossard performed all mice experiments. Mirja Harms and Jan Münch coordinated the whole study and wrote the manuscript with assistance of Frank Kirchhoff.

\section{Conflicts of interest}

Ludger Ständker, Mirja Harms, Ashraf H. Abadi, Monica M.W. Habib, Frank Kirchhoff, Elsa Sanchez-Garcia, Pandian Sokkar and Jan Münch are coinventors of patents claiming the use of EPI$\mathrm{X} 4$ and derivatives for the therapy of CXCR4 associated diseases.

\section{Appendix A. Supporting information}

Supporting information to this article can be found online at https://doi.org/10.1016/j.apsb.2020.12.005.

\section{References}

1. Cavallero S, Shen H, Yi C, Lien CL, Kumar-Ram S, Sucov H. CXCL12 signaling is essential for maturation of the ventricular coronary endothelial plexus and establishment of functional coronary circulation. Dev Cell 2015;33:469-77.

2. Ara T, Tokoyoda K, Okamoto R, Koni PA, Nagasawa T. The role of CXCL12 in the organ-specific process of artery formation. Blood 2005; 105:3155-61.

3. Salcedo R, Oppenheim JJ. Role of chemokines in angiogenesis: CXCL12/SDF-1 and CXCR4 interaction, a key regulator of endothelial cell responses. Microcirculation 2003;10:359-70.

4. Nie Y, Waite J, Brewer F, Sunshine MJ, Littman D, Zou YR. The role of CXCR4 in maintaining peripheral B cell compartments and humoral immunity. J Exp Med 2004;200:1145-56.

5. Petit I, Ponomaryov T, Zipori D, Tsvee L. G-CSF induces stem cell mobilization by decreasing bone marrow SDF-1 and up-regulating CXCR4. Nat Immunol 2002;3:687-94.

6. Chatterjee S, Behnam-Azad B, Nimmagadda S. The intricate role of CXCR4 in cancer. Adv Cancer Res 2014;124:31-82.

7. Xiang Z, Zou ZJ, Zhang XH, Wei ZW, Zhu JT, Yu J, Chen W, He Y, Schwarz RE, Brekken RA, Awasthi N, Zhang CH. A positive crosstalk between CXCR4 and CXCR2 promotes gastric cancer metastasis. Oncogene 2017;36:5122-33.

8. Bonham LW, Karch CM, Fan CC, Tan C, Geier GE, Wang Y, et al. CXCR4 involvement in neurodegenerative diseases. Transl Psychiatry 2018;8:73.

9. García-Cuesta EM, Santiago CA, Vallejo-Díaz J, Juarranz Y, Redríguez-Frade JM, Mellado M. The role of the CXCL12/CXCR4/ACKR3 axis in autoimmune diseases. Front Endocrinol 2019;10:585.

10. Abboud D, Hanson J. Chemokine neutralization as an innovative therapeutic strategy for atopic dermatitis. Drug Discov Today 2017;22: 702-11. 
11. Nagase H, Kudo K, Izumi S, Ohta K, Kobayashi N, Yamaguchi M, et al. Chemokine receptor expression profile of eosinophils at inflamed tissue sites: decreased CCR3 and increased CXCR4 expression by lung eosinophils. J Allergy Clin Immunol 2001;108:563-9.

12. Tahirovic YA, Pelly S, Jecs E, Miller E, Sharma S, Liotta D, et al. Small molecule and peptide-based CXCR4 modulators as therapeutic agents. A patent review for the period from 2010 to 2018. Expert Opin Ther Pat 2020;30:87-101.

13. Micallef I, Stiff P, DiPersio J, Maziarz RT, McCarty JM, Angell J, et al. Successful stem cell mobilization rescue by AMD3100 (Plerixafor) + G-CSF for patients who failed primary mobilization: Results from the phase III (3101-NHL) study. Blood 2007;110:602.

14. de Clercq E. Mozobil® (Plerixafor, AMD3100), 10 years after its approval by the US Food and Drug Administration. Antivir Chem Chemother 2019;27:204020661982938.

15. Holgate ST. Pathogenesis of asthma. Clin Exp Allergy 2008;38: 872-97.

16. Brightling CE, Symon F, Birring S, Bradding P, Wardlaw AJ, Pavord ID, et al. Comparison of airway immunopathology of eosinophilic bronchitis and asthma. Thorax 2003;58:528-32.

17. Barrett NA, Austen KF. Innate cells and T helper 2 cell immunity in airway inflammation. Immunity 2009;31:425-37.

18. Brussino L, Heffler E, Bucca C, Nicola S, Rolla G. Eosinophils target therapy for severe asthma: critical points. BioMed Res Int 2018;2018: 7582057.

19. Negrete-García MC, Velazquez A, Popoca-Coyotl A, MontesVizuet AR, Juarez-Carvajal E, Teran LM, et al. Chemokine (C-X-C motif) ligand 12/stromal cell-derived factor-1 is associated with leukocyte recruitment in asthma. Chest 2010;138:100-6.

20. Nagase H, Miyamasu M, Yamaguchi M, Fujisawa T, Ohta K, Yamamoto K, Morita Y, Hirai K. Expression of CXCR4 in eosinophils: Functional analyses and cytokine-mediated regulation. $J$ Immunol 2000; 164:5935-43.

21. Gonzalo JA, Lloyd CM, Peled A, Delaney T, Coyle AJ, GutierrezRamos JC. Critical involvement of the chemotactic axis CXCR4/stromal cell-derived factor- $1 \alpha$ in the inflammatory component of allergic airway disease. J Immunol 2000;165:499-508.

22. Hachet-Haas M, Balabanian K, Rohmer F, Pons F, Franchet C, Lecat $\mathrm{S}$, et al. Small neutralizing molecules to inhibit actions of the chemokine CXCL12. J Biol Chem 2008;283:23189-99.

23. Gasparik V, Daubeuf F, Hachet-Haas M, Rohmer F, Gizzi P, Haiech J, et al. Prodrugs of a CXC chemokine-12 (CXCL12) neutraligand prevent inflammatory reactions in an asthma model in vivo. ACS Med Chem Lett 2012;3:10-4.

24. Daubeuf F, Hachet-Haas M, Gizzi P, Gasparik V, Bonnet D, Utard V, Hibert M, Frossard N, Galzi JL. An antedrug of the CXCL12 neutraligand blocks experimental allergic asthma without systemic effect in mice. J Biol Chem 2013;288:11865-76.

25. Lukacs NW, Berlin A, Schols D, Skerlj RT, Bridger GJ. AMD3100, a CXCR4 antagonist, attenuates allergic lung inflammation and airway hyperreactivity. Am J Pathol 2002;160:1353-60.

26. Zgraggen S, Huggenberger R, Kerl K, Detmar M. An important role of the SDF-1/CXCR4 axis in chronic skin inflammation. PLoS One 2014; 9:e93665.

27. Takekoshi T, Wu X, Mitsui H, Tada Y, Kao MC, Sato S, Dwinell Hwang ST. CXCR4 negatively regulates keratinocyte proliferation in IL-23-mediated psoriasiform dermatitis. J Invest Dermatol 2013;133: 2530-7.

28. Griffiths CEM, van de Kerkhof P, Czarnecka-Operacz M. Psoriasis and atopic dermatitis. Dermatol Ther 2017;7:31-41.

29. Homey B, Steinhoff M, Ruzicka T, Leung DYM. Cytokines and chemokines orchestrate atopic skin inflammation. J Allergy Clin Immunol 2006;118:178-89.

30. Weidinger S, Novak N. Atopic dermatitis. Lancet 2016;387:1109-22.

31. Guttman-Yassky E, Bissonnette R, Ungar B, Suarez-Farinas M, Ardeleanu M, Esaki H, Suprun M, et al. Dupilumab progressively improves systemic and cutaneous abnormalities in patients with atopic dermatitis. J Allergy Clin Immunol 2019;143:155-72.

32. Coondoo A, Phiske M, Verma S, Lahiri K. Side-effects of topical steroids: a long overdue revisit. Indian Dermatol Online J 2014;5: 416.

33. Zirafi O, Kim KA, Ständker L, Mohr KB, Sauter D, Heigele A, Kluge SF, et al. Discovery and characterization of an endogenous CXCR4 antagonist. Cell Rep 2015;11:737-47.

34. Buske C, Kirchhoff F, Münch J. EPI-X4, a novel endogenous antagonist of CXCR4. Oncotarget 2015;6:35137-8.

35. Müller JA, Zirafi O, Roan NR, Lee SJ, Münch J. Evaluation of EPI-X4 as a urinary peptide biomarker for diagnosis and prognosis of late acute GvHD. Bone Marrow Transplant 2016;51:1137-9.

36. Zirafi O, Hermann PC, Münch J. Proteolytic processing of human serum albumin generates EPI-X4, an endogenous antagonist of CXCR4. J Leukoc Biol 2016;99:863-8.

37. Humphrey W, Dalke A, Schulten K. VMD: visual molecular dynamics. J Mol Graph 1996;14:33-8.

38. Harms M, Gilg A, Ständker L, Beer A, Mayer B, Gruber C, Münch J. Microtiter plate-based antibody-competition assay to determine binding affinities and plasma/blood stability of CXCR4 ligands. Sci Rep 2020;10:16036.

39. Pozzobon T, Goldoni G, Viola A, Molon B. CXCR4 signaling in health and disease. Immunol Lett 2016;177:6-15.

40. Abdelrasoul H, Vadakumchery A, Werner M, Lenk L, Khadour A, Young M, et al. Synergism between IL7R and CXCR4 drives BCRABL induced transformation in Philadelphia chromosome-positive acute lymphoblastic leukemia. Nat Commun 2020;11:3194.

41. Thalhamer T, McGrath MA, Harnett MM. MAPKs and their relevance to arthritis and inflammation. Rheumatology 2007;47:409-14.

42. Hers I, Vincent EE, Tavaré JM. Akt signalling in health and disease. Cell Signal 2011;23:1515-27.

43. Downward J. Targeting RAS signalling pathways in cancer therapy. Nat Rev Cancer 2003:3:11-22.

44. Raldúa D, Piña B. In vivo zebrafish assays for analyzing drug toxicity. Expet Opin Drug Metabol Toxicol 2014;10:685-97.

45. Morash MG, Douglas SE, Robotham A, Ridley CM, Gallant JW, Soanes KH. The zebrafish embryo as a tool for screening and characterizing pleurocidin host-defense peptides as anti-cancer agents. Dis Model Mech 2011;4:622-33.

46. Travers J, Rothenberg ME. Eosinophils in mucosal immune responses. Mucosal Immunol 2015;8:464-75.

47. Li M, Herner P, Zhang Z, Kato S, Metzger D, Chambon P. Topical vitamin D3 and low-calcemic analogs induce thymic stromal lymphopoietin in mouse keratinocytes and trigger an atopic dermatitis. Proc Natl Acad Sci U S A 2006;103:11736-41.

48. Chen H, Xu X, Teng J, Chen S, Bunjhoo H, Cao Y, Liu J. CXCR4 inhibitor attenuates ovalbumin-induced airway inflammation and hyperresponsiveness by inhibiting Th17 and Tc17 cell immune response. Exp Ther Med 2016;11:1865-70.

49. Doyle TM, Ellis R, Park HJ, Inman MD, Sehmi R. Modulating progenitor accumulation attenuates lung angiogenesis in a mouse model of asthma. Eur Respir J 2011;38:679-87.

50. Choi Y, Pham DL, Lee DH, Lee SH, Kim SH, Park HS. Biological function of eosinophil extracellular traps in patients with severe eosinophilic asthma. Exp Mol Med 2018;50:104.

51. Xu J, Mora A, Shim H, Stecenko A, Brigham KL, Rojas M. Role of the SDF-1/CXCR4 axis in the pathogenesis of lung injury and fibrosis. Am J Respir Cell Mol Biol 2007;37:291-9.

52. Li F, Xu X, Geng J, Wan X, Dai H. The autocrine CXCR4/CXCL12 axis contributes to lung fibrosis through modulation of lung fibroblast activity. Exp Ther Med 2020;19:1844-54.

53. Wu B, Chien E, Mol C, Fenalti G, Liu W, Katritch V, Abagyan R, Brooun A, et al. Structures of the CXCR4 chemokine GPCR with small-molecule and cyclic peptide antagonists. Science 2010;330: $1066-71$. 
54. Veldkamp CT, Seibert C, Peterson F, De la Cruz NB, Haugner JC, Basnet H, et al. Structural basis of CXCR4 sulfotyrosine recognition by the chemokine SDF-1/CXCL12. Sci Signal 2008;1:ra4.

55. Dominguez C, Boelens R, Bonvin AMJJ. HADDOCK: A protein-protein docking approach based on biochemical or biophysical information. J Am Chem Soc 2003;125:1731-7.

56. van Zundert GCP, Rodrigues JPGLM, Trellet M, Schmitz C, Kastritis PL, Karaca E, et al. The HADDOCK2.2 webserver: userfriendly integrative modeling of biomolecular complexes. J Mol Biol 2016;428:720-5.
57. Rieping W, Habeck M, Bardiaux B, Bernard A, Malliavin TE, Nilges M, et al. ARIA2: automated NOE assignment and data integration in NMR structure calculation. Bioinformatics 2007;23:381-2.

58. Storch B, Meixlsperger S, Jumaa $H$. The Ig- $\alpha$ ITAM is required for efficient differentiation but not proliferation of pre-B cells. Eur $J$ Immunol 2007;37:252-60.

59. Balabanian $\mathrm{K}$, Lagane $\mathrm{B}$, Infantino $\mathrm{S}$, Chow $\mathrm{K}$, Harriague $\mathrm{J}$, Moepps B, et al. The chemokine SDF-1/CXCL12 binds to and signals through the orphan receptor RDC1 in T lymphocytes. $J$ Biol Chem 2005;280:35760-6. 